Published in final edited form as:

Mol Pharm. 2019 October 07; 16(10): 4165-4180. doi:10.1021/acs.molpharmaceut.9b00496.

\title{
Effect of Particle Formation Process on Characteristics and Aerosol Performance of Respirable Protein Powders
}

\author{
Ashlee D. Brunaugh ${ }^{\ddagger}$, Tian Wu ${ }^{\dagger}$, Sekhar R. Kanapuram ${ }^{\dagger}$, Hugh D. C. Smyth ${ }^{\star}, \ddagger$ \\ ¥College of Pharmacy, The University of Texas at Austin, 2409 West University Avenue, PHR \\ 4.214, Austin, Texas 78712, United States \\ †Amgen, One Amgen Center Drive, Thousand Oaks, California 91320, United States
}

\begin{abstract}
Pulmonary delivery of biopharmaceuticals may enable targeted local therapeutic effect and noninvasive systemic administration. Dry powder inhaler (DPI) delivery is an established patientfriendly approach for delivering large molecules to the lungs; however, the complexities of balancing protein stability with aerosol performance require that the design space of biopharmaceutical DPI formulations is rigorously explored. Utilizing four rationally selected formulations obtained using identical atomization conditions, an extensive study of the effect of the particle formation process (spray drying or spray freeze-drying) on powder properties, aerosol performance, and protein stability was performed. Multiple linear regression analysis was used to understand the relationship between powder properties, device dispersion mechanism, and aerosol performance. Spray drying and spray freeze-drying, despite the same spraying conditions, produced powders with vastly different physical characteristics, though similar aerosol performance. The resulting regression model points to the significance of particle size, density, and surface properties on the resulting aerosol performance, with these factors weighing differently according to the device dispersion mechanism utilized (shear-based or impactionbased). The physical properties of the produced spray dried and spray freeze-dried powders have differing implications for long-term stability, which will be explored extensively in a future study.
\end{abstract}

\section{Graphical Abstract}

\footnotetext{
*Corresponding Author Tel: 512-471-3383. hugh.smyth@austin.utexas.edu. Author Contributions

The manuscript was written through contributions of all authors. All authors have given approval to the final version of the manuscript. ASSOCIATED CONTENT

Supporting Information

The Supporting Information is available free of charge on the ACS Publications website at DOI: 10.1021/acs.molpharma-ceut. $9 \mathrm{~b} 00496$.

Supplementary Figure 1 is a schematic of the spray freeze-drying process setup. Supplementary Figure 2 describes the changes in the particle size distribution of SFD powders at varying dispersion pressures (PDF)

The authors declare the following competing financial interest(s): An author (H.D.C.S.) of this paper consults for and has equity ownership in Respira Therapeutics, Nob Hill Therapeutics, and Via Therapeutics, LLC on inhaled product development. An author of this paper (A.D.B.) is an employee of Via Therapeutics, LLC. The terms of this arrangement have been reviewed and approved by the University of Texas at Austin in accordance with its policy on objectivity in research.
} 


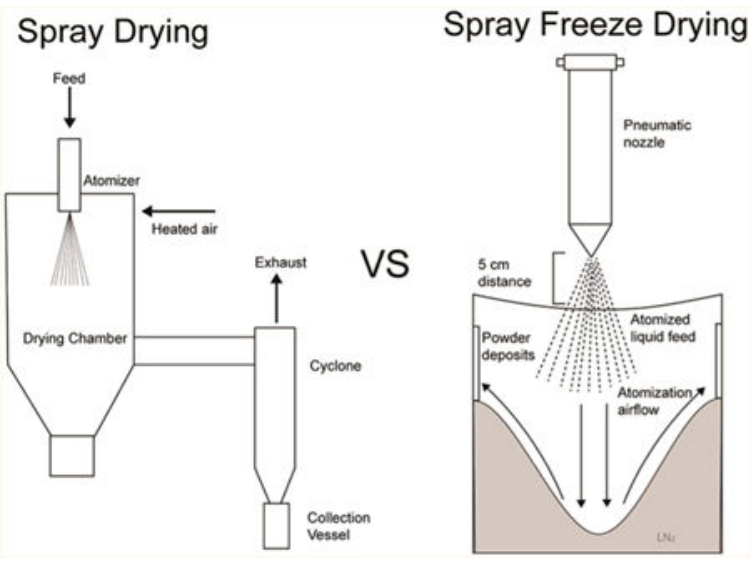

\section{Keywords \\ particle engineering; biopharmaceutical; pulmonary drug delivery; spray freeze-drying; spray drying; dispersibility}

\section{INTRODUCTION}

Pulmonary delivery is an attractive route for administration of biopharmaceuticals such as monoclonal antibodies (mAbs). The lung exhibits an enormous surface area for absorption, ranging from 30 to $140 \mathrm{~m}^{2}$ depending on expiration and inspiration activities. ${ }^{1}$ The large surface area of the lungs enables noninvasive systemic delivery of proteins, as evident by the successful clinical observations and subsequent regulatory approval of inhaled insulin. Significantly, pulmonary delivery of biopharmaceuticals can also be used in the targeted treatment of respiratory diseases. This potential for targeted therapeutic effect was demonstrated in a recent in vivo study performed by Guillon et al., which utilized microdialysis of the lung interstitial fluid to determine pharmacokinetics of a mAb after pulmonary delivery. ${ }^{2}$ High concentrations of $\mathrm{mAb}$ in the lung interstitium were achieved after nebulized delivery, which was coupled with limited and slow passage of the mAb into the bloodstream. The potential for targeted deliver is especially promising for biologics with an extensive systemic adverse effect profile. For example, in vivo delivery of aerosolized cetuximab, a biopharmaceutical used in the treatment of lung cancer, has been achieved with limited absorption of mAb to the bloodstream. ${ }^{3}$ Sustained residence time in the lung is also possible; Rahhal et al. demonstrated that pulmonary delivery of butyrylcholinesterase dry powder resulted in residence time of $48 \mathrm{~h}$ in the lungs and bronchoalveolar lavage fluid. ${ }^{4}$

Development of dry powder inhaler (DPI) formulations of biopharmaceuticals carries additional advantages to those already conferred by the inhalation route. Biopharmaceuticals for injectable administration have long been formulated as solid-state lyophilized products to improve stability. Elimination of water from the product enables protection against hydrolytic reactions that peptides and proteins are prone to, such as deamidation, proteolysis, and racemization. ${ }^{5}$ Compared to nebulized therapy, improved patient compliance may occur as a result of rapid administration time. However, development of a DPI biopharmaceutical formulation presents increased complexities compared to 
development of a small molecule formulation. Formulation and particle engineering techniques that are utilized in the delivery of small molecules to the lung may not be applicable to the delivery of large molecules in which the formulation composition, processing techniques, and delivery method must be optimized to maintain the stability of a labile molecule while still ensuring adequate aerosol performance to deliver a high drug payload to the lungs.

For the production of respirable biopharmaceutical powders, two processes in particular have been heavily utilized: spray drying and spray freeze-drying. ${ }^{6-8}$ Spray drying has been widely established for the formulation of stable dry powder biologics and has resulted in an FDA-approved inhaled insulin product, Exubera. ${ }^{9}$ Spray drying involves three main steps: 1 ) atomization of a liquid feed into droplets, 2) rapid evaporation of solvent from the droplet, and 3) transfer of the particles by carrying air to a collection chamber. ${ }^{10}$ An additional secondary drying step, in which the particles are dried under vacuum, may also be incorporated to further reduce moisture levels in the resulting powder. ${ }^{11}$ Spray drying offers extensive capabilities for engineering customized particles that are suited for pulmonary delivery. End particle properties are influenced by equipment parameters, such as feed flow rate, drying air rate, drying chamber temperature, and atomization energy, as well as components of the formulation and their relative solubility within the feed solvent and solid content of the feed. ${ }^{12,13}$

Spray freeze-drying typically refers to the atomization of a liquid feed into the vapor phase above a cryogenic liquid, which results in ultrarapid freezing of the droplets. ${ }^{14}$ The freezing process is then followed by drying of the formulation in a lyophilizer, which removes water though sublimation (primary drying phase) and desorption (secondary drying phase) over the course of several days. ${ }^{15}$ As water is removed from the product, a honeycomb-like structure is left behind, the characteristics of which are dependent upon the nature of the droplet atomization and freezing process ${ }^{16,17}$ as well as the formulation composition. ${ }^{18}$ Compared to traditional lyophilization processes, spray freeze-drying enables some control of particle size distribution, ${ }^{16}$ which makes it a favorable process for generating biologic powders for pulmonary delivery.

A direct comparison of spray drying and spray freeze-drying processing techniques would be highly beneficial in examining the design space of respirable biopharmaceutical powders. By keeping the droplet formation conditions constant, and instead focusing on the particle formation aspect of the manufacturing process, a modular design space optimization approach can be developed. This could allow mixing and matching of different aspects of the process to fit the needs of a particular molecule and may reduce overall manufacturing costs by supporting development of a platform delivery technology for multiple types of biopharmaceuticals. Few studies have directly compared these two processes for producing respirable biologic powders. ${ }^{7,19,20}$ Utilizing the same atomization conditions, an early study by Maa et al. ${ }^{7}$ compared the effect of the drying process on powder characteristics and aerosol performance using deoxyribonuclease (rhDNase) and anti-IgE monoclonal antibody (anti-IgE mAb) as model proteins. For powders formulated free of excipients, the spray freeze-dried (SFD) powders exhibited larger median particle size, larger specific surface area (SSA), and higher fine particle fraction than spray dried (SD) powders when blended with 
lactose carrier particles and dispersed from a Dryhaler DPI. The improvement in aerosol performance of the SFD powders was hypothesized to be a result of the decreased aerodynamic particle size, an effect of the much lower density of the SFD powders. ${ }^{7}$ Addition of excipients such as trehalose to the formulations resulted in some changes in SFD particle morphology such as loss of porosity, which resulted in decreases in aerosol performance. A direct comparison of the two processes on the stability of the protein models was not performed. Nguyen et al. ${ }^{19}$ compared spray drying and spray freeze-drying processes for the production of 45/25/30\% darbepoetin alfa/trehalose/sodium phosphate particles for later encapsulation in a polymeric microsphere. The study utilized atomization via ultrasonic probe for spray freeze-drying, and atomization via a $0.7 \mathrm{~mm}$ two-fluid nozzle for spray drying. Utilizing ion exchange-size-exclusion chromatography, UV/vis spectroscopy, and gel electrophoresis, it was determined that the darbepoetin alfa SFD powders exhibited increased insoluble and soluble aggregates compared to the SD powders. This was hypothesized to be a result of surface denaturation at the liquid-ice interface or shear associated with phase separation during the spray-freezing process. ${ }^{19} \mathrm{~A}$ study by Saluja et al. ${ }^{20}$ examined the effect of spray drying and spray freeze-drying on the stability, aerosol performance, and immunogenicity of an influenza subunit vaccine powder for inhalation. It was determined that the two drying processes required different buffers to maintain stability of the protein, likely due to differing temperatures causing different changes in $\mathrm{pH}$. Fine particle fraction (FPF) of the powders from the Twincer device studies was $37 \%$ for SD powder and $23 \%$ for SFD powder. For both processes, potency of the vaccine was maintained after 3 years of storage.

The current study expands upon the groundwork laid by these previous studies. Previously, our group used a constrained-mixture design of experiments (DoE) approach to generate 10 formulations based upon the most commonly used excipients in solid-state biopharmaceutical preparations. These formulations were processed using spray freezedrying, and a systematic screening approach was then utilized to identify four formulations with adequate protein stability and aerosol performance. ${ }^{21}$ Using lysozyme as a model protein, these four formulations (F2, F4, F6, and F10) are utilized in part I of the current study to exhibit the specific effect of the particle formation process on the physical characteristics and aerosol performance of the resulting powders. The robustness of the study is increased by verifying the effects of the particle formation processes across four formulations of varying composition. Additionally, whereas previous studies have only utilized one device to assess aerosol performance, the current study utilizes two devices with different powder dispersion mechanisms; the RS01 high resistance DPI (RS01-HR) and the Handihaler DPI. ${ }^{22}$ It has been previously reported that aerosol performance is highly dependent upon the relationship between powder and device, and powders may exhibit differing degrees of respirable dose according to the device dispersion mechanisms utilized. 23,24 Our hypothesis was that formulation composition and particle formation method will impact the physical properties of the powders and result in differences in aerodynamic performance according to the device dispersion mechanism utilized. Appropriate matching of the dispersion mechanism with the physical characteristics of the powder may further improve lung deposition. Though known to be relatively stable, lysozyme serves as a good model protein for this initial screening of drying process effects on powder characteristics 
and aerosol performance, based upon its availability and low-cost. Part II of this study will compare spray drying and spray freeze-drying on the basis of protein stability by incorporating a monoclonal antibody into the most optimal formulation identified in this study and then examining the immediate and long-term effects on protein structural stability.

\section{EXPERIMENTAL SECTION}

\subsection{Composition of Formulations.}

Four formulations (Table 1), consisting of varying amounts of lysozyme, sucrose, and Dmannitol in either 1 or $10 \% \mathrm{w} / \mathrm{v}$ liquid feeds, were subjected to spray drying and spray freeze-drying processes, resulting in the generation of eight powders. Formulation composition was based on a previously published constrained mixture DoE, ${ }^{21}$ which utilized sucrose and mannitol as lyoprotectants/cryoprotectants, polysorbate 80 as a surfactant, and histidine as a buffer. In this study, Ferrati et al. ${ }^{21}$ found that a composition of at least $60 \%$ lysozyme was necessary to achieve a respirable, stable formulation using a spray freezedrying process. Thus, our study utilized four formulations containing $60 \%$ lysozyme generated from this previous DoE that were concluded to have suitable aerosol performance. ${ }^{21}$ Lysozyme from chicken egg white, D-mannitol, sucrose, polysorbate 80, and histidine were purchased from Sigma. Twice-filtered deionized water was used to dissolve the formulation components. The final $\mathrm{pH}$ of the liquid formulations was around 5 . Though $\mathrm{pH}$ is an important consideration in the development of a stable formulation, the $\mathrm{pH}$ was not adjusted further in this particular study, as the objective was to examine the resulting powder characteristics and aerosol performance, rather than explore long-term protein stability.

\subsection{Atomization Characterization.}

Atomization parameters were set at $1 \mathrm{~mL} / \mathrm{min}$ feed rate and $17.5 \mathrm{~L} / \mathrm{min}$ atomization air flow rate through a $0.7 \mathrm{~mm}$ two-fluid pneumatic nozzle (BUCHI Corporation, New Castle, DE, USA). Compressed nitrogen was used as the atomization gas. A low feed rate was chosen to reduce shear stress on the fragile biologic formulation component, lysozyme, while a high atomization flow rate was chosen to ensure production of dried particles of a respirable size. 11,17 To ensure atomization conditions could be reproduced in both processes, an external syringe pump (KD Scientific, Holliston, MA, USA) and external flow meter (Copley Scientific, Colwick, Nottingham, UK) were utilized to set the feed rate and atomization rate. Preliminary experiments demonstrated that the inclusion of the cleaning needle in the BUCHI nozzle unit generated negative pressure that led to disruption of the feed rate; therefore, the cleaning needle was removed from the nozzle for all experiments. To determine the primary droplet size of the atomized feed, the plume generated by the nozzle was set inline with a HELOS laser diffraction unit (Sympatec GmbH, Clausthal-Zellerfeld, Germany). The plume was characterized at varying nozzle distances from the laser center (3, 5 , and $7 \mathrm{~cm}$ ) over the course of $60 \mathrm{~s}$. Mie theory with a refractive index of 1.33 for water and 1.00 for air was used to solve for the droplet size distribution, and the goodness of fit of the model was assessed by the HELOS/R software. Distributions with a model fit less than 0.97 were discarded. The $5 \mathrm{~cm}$ distance was found to result in the best model fit, and this distance was used for the final droplet size analysis. 


\subsection{Spray Drying and Spray Freeze-Drying Processes.}

Spray drying was conducted using a BUCHI B-290 lab scale spray dryer at an inlet temperature of $130^{\circ} \mathrm{C}$. Dehumidified air was used as the drying medium, at a drying air rate of $35 \mathrm{~m}^{2} / \mathrm{h}$. The resulting outlet temperature of $85-90{ }^{\circ} \mathrm{C}$ aligned with similar studies on the spray drying of biopharmaceuticals. ${ }^{25}$ Due to the potential for heat generated from the drying process to result in degradation of lysozyme, the nozzle, cyclone, and collection vessel regions of the spray dryer were chilled to $4{ }^{\circ} \mathrm{C}$ during the duration of the process.

Atomization parameters used in spray drying were also used for spray freeze-drying. The BUCHI two-fluid nozzle was positioned $5 \mathrm{~cm}$ above a cryogenic chamber containing approximately $500 \mathrm{~g}$ of liquid nitrogen $\left(\mathrm{LN}_{2}\right)$. A vacuum was positioned near the nozzle tip to draw $\mathrm{LN}_{2}$ vapor away from the nozzle and prevent freezing of the nozzle (Supporting Figure 1). To maintain the cryogenic nature of the chamber, additional $\mathrm{LN}_{2}$ was added every 10 min during the course of the process, and any powder build-up on the walls of the cryogenic chamber was scraped into the $\mathrm{LN}_{2}$ at the bottom of the chamber. At the conclusion of the spray process, an amount of $\mathrm{LN}_{2}$ sufficient to form a slurry with the powder was added to the chamber. The slurry was then aliquoted into $50 \mathrm{~mL}$ conical vials and lyophilized using a manifold lyophilizer (LabConco, Kansas City, MO, USA) at $<0.1$ mbar pressure and ambient temperatures over $72 \mathrm{~h}$.

\subsection{Particle Sizing.}

Particle size distribution (PSD) was assessed using a HELOS laser diffractor coupled with a RODOS dry dispersion unit. Measurements were taken every $5 \mathrm{~ms}$ during the period when the optical concentration was greater than $1 \%$. The PSD was solved using Fraunhofer theory. The PSD for each measurement between 5 and $25 \%$ optical concentration was averaged to obtain the overall PSD for the sample. Powder dispersibility profiles were obtained by measuring PSD at stepwise increases in RODOS dispersion pressure ( 0.2 to 4.5 bar), using a method adapted from Jaffari et al. ${ }^{26}$

\subsection{Scanning Electron Microscopy (SEM).}

SEM images of the powders were obtained using a Zeiss Supra 40VP SEM (Carl Zeiss Microscopy $\mathrm{GmbH}$ ). Powder samples were mounted on aluminum SEM stubs using doublesided carbon tape, and then sputter coated with 15-20 nm of platinum/palladium (Pt/Pd) under argon using a Cressington sputter coater 208 HR (Cresssington Scientific Instruments Ltd., Watford, UK). To compare the morphology of undispersed powders versus fully dispersed powders, a second set of samples was prepared in which the powder was dispersed onto double-sided tape using the RODOS disperser at 4 bar pressure. Imaging proceeded as previously described.

\subsection{Surface Area Analysis.}

The specific surface area (SSA) of the formulations was measured using a Monosorb Gas Adsorption unit (Quantachrome, Boynton Beach, FL, USA) and single point BraummerEmmett-Teller (BET) method. A known quantity of powder was outgassed under helium at $40{ }^{\circ} \mathrm{C}$ for $24 \mathrm{~h}$ prior to gas adsorption analysis. This outgassing temperature was selected to reduce the risk of heat-related degradation of the powders, while still promoting water vapor 
removal. For SFD powders, preliminary analysis indicated that this outgassing procedure was insufficient to fully remove adsorbed moisture. Therefore, an additional preliminary step of drying the powders for $24 \mathrm{~h}$ under vacuum was incorporated. To ensure full removal of impurities, adsorption-desorption cycles were repeated until consecutive surface area measurements differed by less than $5 \%$. The resulting surface area value was then normalized to the sample weight to obtain the SSA. The rugosity index (RI) of the powders was calculated as the ratio of the measured surface area (derived from the SSA, the true density, and the theoretical volume of the particles based upon median particle size) to the theoretical surface area (based upon the surface area of a sphere of equivalent diameter to the particles).

\subsection{Pycnometry (True) Density.}

The true density of the processed powders was calculated using a helium multipycnometer (Quantachrome Instruments) and micro sample cell. The sample cell was filled to at least $75 \%$ of total volume with powder. Samples were outgassed under vacuum at ambient temperature for $24 \mathrm{~h}$. The pressure of both the reference cell $\left(P_{1}\right)$ and sample cell $\left(P_{2}\right)$ were determined, and the true volume of the sample was calculated according to eq 1 :

$$
V_{\mathrm{p}}=V_{\mathrm{c}}-V_{\mathrm{R}}\left[\left(\frac{P_{1}}{P_{2}}\right)-1\right]
$$

For the micro-sample cell utilized, $V_{\mathrm{c}}$ was calibrated at $11.76156 \mathrm{~cm}^{3}$ and $\mathrm{V}_{R}=6.34216$ $\mathrm{cm}^{3}$. True density was obtained by dividing the outgassed sample weight by the measured true volume. To ensure full removal of impurities from pores, measurements were repeated until the standard deviation of ten consecutive true density measurements was less than 0.01 $\mathrm{g} / \mathrm{mL}$.

\subsection{Bulk and Tapped Density.}

To determine bulk density of the powders, a $1 \mathrm{~mL}$ flat-bottomed sample tube was calibrated to $0.25 \mathrm{~mL}$ marks using a $1000 \mu \mathrm{L}$ micropipette. A $10 \mathrm{~mL}$ cylinder was initially used to perform bulk and tapped density measurements; however, the limited amount of powder available for analysis reduced the accuracy of the measurement. A $1 \mathrm{~mL}$ volume was therefore selected instead for this preliminary study. Powder was slowly poured into the vessel until the $1.00 \mathrm{~mL}$ mark was reached and then weighed. To determine tapped density, powder was tapped 50 times, and the volume was recorded. Preliminary analysis indicated that powder volume did not change after 50 taps using the $1 \mathrm{~mL}$ sample vessel. Bulk density and tapped density analysis were performed in triplicate. To assess powder flowability, the compressibility index (CI) of the powders was calculated from the bulk and tapped density according to eq 2 . 


$$
\mathrm{CI}=\frac{100\left(\rho_{\text {tapped }}-\rho_{\text {bulk }}\right)}{\rho_{\text {tapped }}}
$$

\subsection{Water Content.}

Water content of the processed formulations was assessed using thermogravimetric analysis (TGA). Powder samples were loaded into a $70 \mu \mathrm{L}$ alumina crucible with a pierced covering to reduce static evaporation. Approximately $6 \mathrm{mg}$ of SD powder was loaded in the crucible, while approximately $3 \mathrm{mg}$ of SFD powder was loaded due to the lower powder density. Powder samples were heated from 30 to $200{ }^{\circ} \mathrm{C}$ at a rate of $10{ }^{\circ} \mathrm{C} / \mathrm{min}$. Percent water content was determined as the point where weight change in the sample plateaued prior to the start of degradation.

\subsection{Differential Scanning Calorimetry (DSC).}

Thermal analysis of powders was performed using a Q20 DSC (TA Instruments, New Castle, DE, USA). Approximately $6 \mathrm{mg}$ of the SD formulations were loaded into a Tzero pan. For SFD formulations, approximately $3 \mathrm{mg}$ of powder was loaded due to the lower density of the powder. The pans were press-sealed with a hermetic lid, and a hole was then pierced to enable evaporation of water. Pan temperature was first lowered to $10{ }^{\circ} \mathrm{C}$ per minute to $-40{ }^{\circ} \mathrm{C}$, then ramped from -40 to $200^{\circ} \mathrm{C}$ using a modulated DSC cycle of $\pm 0.5^{\circ} \mathrm{C}$ every $40 \mathrm{~s}$ with a ramp rate of $2{ }^{\circ} \mathrm{C}$ per minute. A starting temperature of $-40{ }^{\circ} \mathrm{C}$ was selected to enable accurate detection of any potentially low $T_{\mathrm{g}}$ values. Data was processed using TA Universal Analysis (TA Instruments).

\subsection{X-ray Powder Diffraction (XRD).}

XRD was performed using a Riguku MiniFlex II (Riguku, The Woodlands, TX, USA) equipped with a $\mathrm{Cu}-\mathrm{K} a$ radiation source generated at $40 \mathrm{kV}$ and $15 \mathrm{~mA}$. To obtain diffraction patterns, samples were scanned in continuous mode over the range of $5-45^{\circ}$ at a rate of $1 \% \mathrm{~min}$ and using a step size of $0.025^{\circ}$. Data was processed using Jade (Materials Data, Livermore, CA, USA).

\subsection{Water Sorption.}

Dynamic vapor sorption (DVS) analysis of the formulations was performed using an Automated Water Sorptoin Analyzer (Surface Measurement Systems, London, UK). A sample of 8-10 mg of powder was assessed for each formulation. The glass sample cell containing powder was allowed to equilibrate under nitrogen until completely dry (RH < $0.8 \%, \mathrm{~d} m / \mathrm{d} t<0.002 \%)$. Water sorption was analyzed over the course of 10 steps from $0 \%$ $\mathrm{RH}$ to $75 \% \mathrm{RH}$ where step $\mathrm{d} \mathrm{m} / \mathrm{d} t$ was set at $0.0075 \% / \mathrm{min}$. Two cycles of sorptiondesorption were performed in total for each powder. The degree of hygroscopicity was quantified by applying a modified form of the BET equation to the water sorption data as 
described by Costantino et al. ${ }^{27}$ and Hsu et al. ${ }^{28}$ Powder hygroscopicity was compared on the basis of the slope of the line fitted to the linear portion of the curve.

\subsection{Surface Composition.}

Surface composition of the processed powders and a pure lysozyme SD control was analyzed with X-ray photoelectron spectroscopy (XPS) using a Kratos X-ray Photoelectron Spectrometer (Kratos Analytical Ltd., Manchester, UK). The nitrogen peak area, specifically the N1 region, was used as a marker for lysozyme. Prior to analysis, powders were loaded onto a sample stub and outgassed under ultrahigh vacuum for $48 \mathrm{~h}$ to remove surface impurities. Emission was set to $10 \mathrm{~mA}$, and anode was set to $10 \mathrm{kV}$. A survey measurement from 1200 to $0 \mathrm{eV}$ at dwell time of $300 \mathrm{~ms}$ was performed, followed by acquisition at the carbon (C1) and N1 regions at dwell of $1600 \mathrm{~ms}$. The charge neutralizer was active for all measurements. Peak fitting was performed with CasaXPS (Casa Software Ltd., Teignmouth, UK) using Shirley background subtraction. To normalize measurements for differences in intensity due to variations in sample surface roughness, the N1 peak area was assessed as a percentage of the total peak area contribution for $\mathrm{C} 1$ and N1. Excess surface lysozyme present in the formulations was assessed according to eq 3 , and then the ratio of the measured surface area was normalized to theoretical volume of the particles in the formulation ( $\left.\mathrm{SA}_{\text {measured }} / V_{\text {theoretical }}\right)$.

lysozyme surface excess

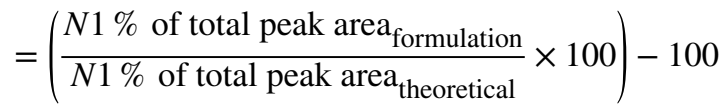

\subsection{Protein Aggregation.}

Size exclusion chromatography (SEC) was performed using a Dionex UltiMate 3000 HPLC System (Thermo Scientific, Sunnyvale, CA) coupled with a TSKgel G3000SWXL column (Tosoh Bioscience LLC, Tokyo, Japan). A previously published method was utilized, ${ }^{21}$ which consisted of an injection volume of $75 \mu \mathrm{L}$ and isocratic elution at a rate of $0.5 \mathrm{~mL} / \mathrm{min}$ using a buffer of $100 \mathrm{mM}$ sodium phosphate and $250 \mathrm{mM}$ chloride adjusted to $\mathrm{pH} 6.8$. UV absorbance at $280 \mathrm{~nm}$ was measured over the course of $35 \mathrm{~min}$. Prior to injection, samples were diluted to approximately $1.2 \mathrm{mg} / \mathrm{mL}$ of lysozyme. To determine if aggregation of lysozyme occurred, the retention time of the peak in the sample chromatogram was compared against a known standard. Relative retention time (RRT) was calculated by dividing the lysozyme standard main peak retention time by the sample main peak retention time. The percent area of each peak in the chromatogram represented the area as a percentage of the total area of all peaks. A decrease in RRT or the appearance of earlier eluting peaks (represented by a decrease in percent peak area of the peak corresponding to the standard peak) was indicative of protein aggregation. Chromeleon Version 6.80 software (Thermo Scientific, Sunnyvale, CA) was used to process all chromatography data. 


\subsection{Aerosol Performance.}

A Next Generation Impactor (NGI) without a preseparator was used to perform cascade impaction analysis of SD and SFD powders. Cascade impaction studies were performed in triplicate for each formulation. To reduce particle bounce, the stages of the NGI were coated with $1 \%(\mathrm{v} / \mathrm{v})$ glycerin in ethanol and allowed to dry prior to testing. Processed powders were dispersed into the apparatus using either a Handihaler or a RS01-HR DPI. Flow rate was set to achieve a pressure drop of $4 \mathrm{kPa}$ in each device. For the RS01 device, this corresponded to a flow rate of $55.6 \mathrm{~L} / \mathrm{min}$, based upon a reported resistance of 0.036 $\mathrm{kPa}^{0.5} \cdot \mathrm{min} / \mathrm{L} .{ }^{29}$ For the Handihaler device, a flow rate of $40.8 \mathrm{~L} / \mathrm{min}$ was used, based upon a reported resistance of $0.049 \mathrm{kPa}^{0.5} \cdot \mathrm{min} / \mathrm{L} .^{22}$ As specified in USP $<601>$, a duration of time sufficient to draw $4 \mathrm{~L}$ of air through the NGI was utilized for each test. ${ }^{30}$ The deposited powder was collected from the inhaler, mouthpiece adapter, induction port, stages $1-7$, and the micro-orifice collector (MOC) by washing with $100 \mathrm{mM}$ sodium phosphate and $250 \mathrm{mM}$ sodium chloride buffer, adjusted to $\mathrm{pH}$ 6.8. The mass of lysozyme in each region of the apparatus was quantified using UV absorbance at a wavelength of $240 \mathrm{~nm}$ using a Tecan Infinite 200 PRO multimode microplate reader (Tecan Systems, Inc., San Jose, CA, USA).

Based upon the flow rate utilized for each device, stage 1-7 cutoff diameters of the NGI were determined using eq 4 . MOC cutoff diameters were determined using eq 5.

$$
\begin{gathered}
D_{50, Q}=D_{50, Q n}\left(\frac{Q_{n}}{Q}\right)^{x} \\
D_{80, Q}=0.14\left(\frac{Q_{n}}{Q}\right)^{1.36}
\end{gathered}
$$

where $D_{50, Q}$ is the cutoff diameter at the flow rate $Q, D_{50, Q n}$ is the cutoff diameter at the archival reference values of $Q_{n}=60 \mathrm{~L} / \mathrm{min}$, and the values for the exponent, $x$, are those obtained from the archival NGI stage cut size-flow rate calculations as determined by Marple et al. ${ }^{31}$

The emitted fraction (EF) for each formulation was calculated as the total amount of lysozyme emitted from the device as a percentage of the total lysozyme collected. The respirable fraction using a $5 \mu \mathrm{m}$ cutoff $\left(\mathrm{RF}_{<5} \mu \mathrm{m}\right)$ and the respirable fraction using a $3 \mu \mathrm{m}$ cutoff $\left(\mathrm{RF}_{<3} \mu \mathrm{m}\right)$ corresponded to the percentage of the total lysozyme collected with an aerodynamic diameter below 5 and $3 \mu \mathrm{m}$, respectively. $\mathrm{RF}_{<5 \mu \mathrm{m}}$ and $\mathrm{RF}_{<3 \mu \mathrm{m}}$ values were interpolated from a graph plotting the cumulative fraction of lysozyme deposited in a stage 
against the cutoff values of the stage. Mass median aerodynamic diameter (MMAD) and geometric standard deviation (GSD) were determined by plotting the cumulative percentage of mass less than an aerodynamic size cutoff (expressed as Probits) against the aerodynamic diameter (log scale). A linear regression was performed to determine the aerodynamic diameters corresponding to the 50th percentile to determine the MMAD, and the 15.87th and 84.13th percentiles to calculated GSD.

To determine how effective the studied DPI devices were at dispersing the powders, an additional aerosol performance metric was calculated, termed the device deagglomeration efficiency or DDE. Though powders may appear to fit the criteria needed for successful lung deposition (small geometric diameter and/or low density), successful dispersion and delivery also requires that the strong cohesive forces between particles are overcome by the deagglomeration forces generated within the device upon patient inhalation. ${ }^{32}$ The intent of the DDE metric was to evaluate how appropriately paired a particular powder was with a device, while accounting for the fact that some powders have a low potential for lung deposition to begin with. A low DDE value indicates that the device is not able to overcome the cohesive forces between particles to reach the highest potential lung deposition dose available for a particular respirable powder. The DDE metric for each formulation with each device was calculated as follows. The geometric diameter corresponding to an aerodynamic particle diameter of $5 \mu \mathrm{m}$ was calculated according to eq 6 :

$$
d_{\mathrm{ae}}=d_{\mathrm{geo}} \sqrt{\frac{\rho_{\mathrm{p}}}{\chi \rho_{0}}}
$$

where $d_{\mathrm{geo}}$ is the geometric diameter of the particle, $\chi$ is the shape factor (assumed 1 for spherical), and $\rho_{\mathrm{p}}$ is the measured tapped density of the powder (assumed equivalent to dispersed particle density including void spaces). To determine the $\%$ of particles under the $d_{\text {geo }}$ corresponding to a $d_{\mathrm{ae}}$ of $5 \mu \mathrm{m}$ when the formulations were fully dispersed, the cumulative particle size distribution for each formulation at 4 bar RODOS dispersion pressure was plotted, and a linear or logarithmic equation was fitted to the points surrounding the geometric size cut of interest. The percentage of particles under this cutoff was solved for using the fitted equation to find the highest $\mathrm{RF}_{<5 \mu \mathrm{m}}$ that could possibly be achieved under full dispersion conditions. The actual $\mathrm{RF}_{<5 \mu \mathrm{m}}$ for each formulation in each device was divided by this optimal $\mathrm{RF}_{<5 \mu \mathrm{m}}$ to determine the DDE.

\subsection{Statistical Analysis.}

Statistical significance of the $\mathrm{EF}, \mathrm{RF}_{<5 \mu \mathrm{m}}$, and $\mathrm{RF}_{<3 \mu \mathrm{m}}$ of each formulation was determined using ANOVA at alpha $=0.05$, followed by Tukey posthoc analysis using Excel (Microsoft, Redmond, WA, USA). Multiple linear regression (MLR) analysis was performed using the opensource software R. ${ }^{33}$ Powder characteristics were used as the independent variables and aerosol performance metrics $\left(\mathrm{EF}, \mathrm{RF}_{<5 \mu \mathrm{m}}, \mathrm{DE}\right)$ as the response variables. Variables with the 
largest $P$-values in the equation were systematically eliminated to determine effect on fit and statistical significance of the equation (adjusted $R 2$ and $p$-value, respectively).

Multicollinearity of the independent variables was assessed by determining the variance inflation factors (VIF), with a goal of VIF < 4 for all the variables. Variables were systematically eliminated by utilizing eigenvalues and identifying variables contributing a large proportion of variance in the eigenvalue (>0.50). Only variables passing the multicollinearity test were used in the regression equation.

\section{RESULTS}

\subsection{Effect of Process on Powder Physical Characteristics.}

The initial droplet size for the formulations tested were similar, with a median diameter ranging from 14.1 to $15.4 \mu \mathrm{m}$ as determined by laser diffraction analysis of the plume generated by the nozzle set in-line with a HELOS laser diffraction (Table 2). The median diameter and span of the distribution for both processes was dependent upon the percentage of solids in the initial liquid preformulation, with F6 and F10 powders (1\% w/v solid formulations) exhibiting a smaller median diameter and more narrow distribution than F2 and F4 (10\% w/v solid formulations) (Figure 1A, Table 2). In contrast, the dispersion profile of the powders was highly dependent upon the particle formation process utilized, rather than the formulation composition (Figure 1B). At very low dispersion pressures ( $<1$ bar), the PSD of SFD powders closely aligned with that of the liquid formulation droplets (Supporting Figure 2); however, increasing dispersion energies resulted in a broadening of the distribution and skewed the distribution toward smaller particles. Full dispersion, which was indicated by a plateau in the particle size versus dispersion pressure profile, was not achieved for SFD powders until the upper range of distribution pressures was reached. In contrast, SD powders exhibited full dispersion at comparatively lower pressures (1.0 bar).

Despite differences in formulation composition, generally all particles produced using the SD process exhibited a spherical, irregular morphology with a dented shell (Figure 2). Undispersed particles exhibited a heterogeneous size distribution, in which smaller particles rested in the dents of larger particles. Dispersion at 4 bar pressure resulted in deagglomeration into primary particles with no apparent changes in morphology. In contrast, the morphology of SFD particles was dependent upon formulation composition. Ten percent solid content formulations (F2 and F4) exhibited a structure that closely resembled the initial droplet. Particles from the F2SFD powder (containing 40\% sucrose) exhibited a wrinkled surface structure with large voids, while those from the F4SFD powder (containing 20/20\% sucrose/mannitol) exhibit smaller voids that are present through the surface and core of the entire particle. One percent solid content formulations (F6 and F10) exhibit diffuse, delicate structures that lack similarities with the original droplet. For all cases, dispersion at 4 bar pressure results in breakage of the initial agglomerates into smaller primary particles. The resulting primary particles were highly irregular with some deviations from sphericity. Differences in surface area are also seen in SEM images, and this is noted in the gas adsorption analysis of the powders. For all formulations, the spray freeze-drying resulted in a higher SSA compared to spray drying (Table 1). It is important to note that the SSA values determined from gas adsorption for the SFD powders appear lower than what is visually

Mol Pharm. Author manuscript; available in PMC 2019 October 18. 
seen in the SEM images in which an extensive internal matrix structure for the particles is noted. This may indicate that the powders could not be fully outgassed and the reported SSA is undervalued. Due to the relatively low $T_{\mathrm{g}}$ of the SFD powders, higher outgassing temperatures could not be utilized without leading to material degradation. The SSA reported in this study may be more accurately thought of as an external SSA measurement of the particles, which would still hold relevance in interpreting trends in particle cohesion and water sorption.

TGA revealed that SFD powders exhibited approximately $1.5 \%$ higher water content than SD powders (Table 2). This may be caused by the larger surface area of the SFD powders adsorbing greater amounts of water prior to TGA measurement or may be artifact of the lyophilizer settings utilized in this study in which longer drying time could be used to further reduce water content. Considering the relatively large water content values for both SD and SFD powders, an additional drying step under vacuum would be appropriate to further reduce water content levels in both processes. DVS demonstrated that all powders were extremely hygroscopic with water sorption profiles that were typical of an amorphous biologic formulation (Figure 3) in which water is absorbed into the bulk material, rather than only adsorbed at the surface. ${ }^{34}$

Pure lysozyme SD was determined to have N1\% peak area of 31.68 using XPS. Given that all formulations contain approximately $58.81 \%$ lysozyme, the theoretical N1\% peak area if no surface protein accumulation occurred (i.e., a fully homogeneous mixture) would be 18.63. Surface excess of lysozyme may be determined by dividing the measured N1\% peak area by the theoretical N1\% peak area. This value is then normalized to the surface area to volume ratio $(\mathrm{SA} / V)$ of the particles, to account for the contribution of surface area differences to surface lysozyme content measurements. Normalized values indicated that SFD powders exhibited decreased surface accumulation compared to SD powders (Table 2). For SD powders, lysozyme surface accumulation increased with increasing concentrations of lysozyme in the liquid feed (F2 and F4 vs F6 and F10).

Between different formulations produced using the same particle formation process, there was little difference in the true density measurements. However, analysis of SFD formulations consistently resulted in a value that was $\sim 0.1 \mathrm{~g} / \mathrm{mL}$ higher than SD powders, which may be indicative of incomplete diffusion of helium gas into the highly porous structure of these particles. ${ }^{35}$ The higher true density of SFD particles may also be due to the increased water content. Water acts as plasticizer and may lead to alterations in the structure and free volume between the matrix molecules. ${ }^{36}$ Bulk density of the SFD powders was substantially lower than the SD powders (Table 2). Compared against the true density, this indicates a tremendous amount of void space in the powders produced via both processes, ${ }^{37}$ but more so for the SFD powders. SFD powders exhibited higher compressibility index values, which is indicative of poorer powder flow. ${ }^{38}$

\subsection{Effect of Process on Powder Crystallinity and Glass Transition $\left(T_{g}\right)$ Temperature.}

Diffractograms of the main components of the formulation prior to processing revealed that D-mannitol and sucrose were in a crystalline state, while lysozyme was in an amorphous state (data not shown). Pure sucrose and pure lysozyme powders produced with either 
particle formation process exhibited an amorphous structure, while pure processed mannitol powders remained crystalline (Figure 4). After processing, SD and SFD powders primarily exhibited diffractograms with a diffuse halo, indicative of an amorphous substance. However, the F4SFD powder exhibited partial crystallization, indicated by peaks on the diffractogram. The diffractogram for the F4SD formulation, in contrast, showed a diffuse halo and no discernible crystalline peaks. Intensity peaks at approximately $24.8^{\circ}$ and $25.8^{\circ}$ in the F4SFD formulation align with unique reference pattern peaks for the delta polymorph of mannitol, though these are also known to coincide with peaks for mannitol hemihydrate. 39

DSC was performed on SD and SFD formulations, as well the primary components of the formulations (i.e., pure mannitol, sucrose, and lysozyme). Pure SD sucrose (Figure 5) and SFD sucrose (data not shown) exhibited an exothermic peak at near $130^{\circ} \mathrm{C}$. This peak is eliminated upon the addition of lysozyme to the formulation. SD and SFD formulations exhibit two endothermic peaks. The first peak corresponds to a second $T_{\mathrm{g}}$ temperature noted in all formulations, which is likely the $T_{\mathrm{g}}$ upon evaporation of water. The second endothermic peak in the formulations occurs slightly before the endothermic peak noted in the pure SD sucrose profile. Based upon the decrease in the size of the peak in formulations with a reduced percentage of sucrose (F6 and F10), it is likely that this peak can be attributed to thermal decomposition of sucrose, which has been reported to occur at temperatures near or below the melting point of crystalline sucrose. ${ }^{40}$ Lee et al. reported a decomposition endotherm ending at $184^{\circ} \mathrm{C}$ for amorphous sucrose produced by heatquenching, ${ }^{41}$ which closely matches the endotherm noted in the DSC scans for this study.

\subsection{Effect of Process on Protein Stability.}

SEC was used to assess the protein stability of the formulations. Unprocessed lysozyme (retention time of $23.77 \mathrm{~min}$ ) was used as a control. SD and SFD processes resulted in no protein aggregation for the formulations tested (Table 2).

\subsection{Effect of Process on Aerosol Performance.}

Aerosol performance of the SD and SFD formulations was assessed using two different devices, the Handihaler and RS01-HR device. There was no statistically significant difference between the EF of formulations dispersed using the Handihaler device regardless of formulation composition or drying method. Among formulations of the same composition produced via different drying methods, only F6 had a statistically significant difference in $\mathrm{RF}_{<5 \mu \mathrm{m}}$, with F6SFD having a $22.6 \%$ higher $\mathrm{RF}_{<5 \mu \mathrm{m}}$ than F6SD $(p=0.001)$ and a $14.7 \%$ higher $\mathrm{RF}_{<3 \mu \mathrm{m}}$ (Figure 6).

Statistically significant Handihaler performance differences among formulations of differing composition produced via the same drying process primarily stemmed from the poor aerosolization of the F6SD formulation, with F2SD, F4SD, and F6SD all having a significantly higher $\mathrm{RF}_{<5 \mu \mathrm{m}}$. F2SD and F10SD also had a higher $\mathrm{RF}_{<3 \mu \mathrm{m}}$ at a difference that was statistically significant. However, F4SD, which like F6SD contains D-mannitol, did not have a statistically significant difference in $\mathrm{RF}_{<3 \mu \mathrm{m}}$. 
For SFD formulations, formulations with a $1 \%$ solid content in the liquid feed exhibited improved performance over formulations with $10 \%$ solid content. F10SFD had 13.8\% higher $\mathrm{RF}_{<5 \mu \mathrm{m}}$ than F2SFD $(p=0.029)$. For $\mathrm{RF}_{<3 \mu \mathrm{m}}, \mathrm{F} 6 \mathrm{SFD}$ was $7.9 \%$ higher than F2SFD ( $p=$ $0.042)$, and F10SFD was $10.7 \%$ higher than F2SFD $(p=0.007)$ and $9.3 \%$ higher than F4SFD ( $p=0.009)$. There were no statistically significant differences in the Handihaler performance of F2SFD vs F4SFD (both 10\% solid content formulations) and F6SFD vs F10SFD (both 1\% solid content formulations). Likewise, presence of D-mannitol in the formulation (F2SD versus F4SD and F6SD versus F10SD) did not significantly affect aerosol performance.

MLR analysis was performed to further understand the relationship between characteristics of the SD and SFD formulations and their aerosol performance. The resulting models are shown in Table 3.

\section{DISCUSSION}

\subsection{Spray Drying and Spray Freezing Drying Processes Have Differing Effects on Powder Characteristics Relevant to Protein Stability.}

Excipients play a critical role in promoting the stability of labile biologics during the stressful manufacturing processes required to generate respirable powders. ${ }^{42}$ Commonly used excipients include disaccharides (e.g., sucrose) and polyols (e.g., mannitol) to provide cryoprotectant and lyoprotectant effects, ${ }^{43-45}$ buffers (e.g., histidine) to protect against $\mathrm{pH}$ changes during processing and provide conformational stability, ${ }^{46}$ and surfactants (e.g., polysorbate 80 ) to reduce adsorption of proteins at the air-liquid or ice-water interface. ${ }^{47}$ Though the model protein, lysozyme, that was used in this study is known to be relatively resistant to degradation, these stabilizing excipients were still incorporated in the formulations studied to examine the effect of the particle formation process on their stabilizing properties, as it is likely they will be necessary to incorporate in the manufacturing of more labile biopharmaceuticals, such as monoclonal antibodies. While no lysozyme aggregation was noted within two-weeks of processing (Table 2) or in preliminary stability studies conducted 70 days after processing, some of the powders generated from the SD and SFD processes exhibited potentially concerning characteristics related to crystallinity, $T_{\mathrm{g}}$, and protein surface accumulation that could result in long-term instability.

Despite its frequency of use in lyophilized and spray-dried biopharmaceutical formulations, D-mannitol is reported to have strong tendency to crystallize, ${ }^{48,49}$ though it can exist in partial or fully amorphous form in certain pharmaceutical formulations. ${ }^{50}$ Compared to the XRD pattern for pure SFD and SD mannitol, crystallization is suppressed to a significant extent in both SD and SFD lysozyme formulations (F4 and F6). However, phase separation is noted in the formulation containing the highest amount of mannitol (F4, at $\sim 20 \% \mathrm{w} / \mathrm{w}$ ). The XRD pattern for F4SFD (Figure 4) demonstrates peaks corresponding to literature reported values for the delta polymorph or hemihydrate polymorph of mannitol. ${ }^{39}$ For both F4SD and F4SFD, crystal nucleation can be seen in the SEM images of the dispersed particles (Figure 2). The propensity for mannitol hydrate formation is also noted be found in the DVS profile for the F4SD powder sample, which exhibits a sharp increase in water uptake near 50\% RH. These results suggest that the usage of $20 \%$ mannitol in either SD or 
SFD processes may be too high, and the more conservative level of 10\% (found in the F6 formulation) could be more appropriate in future optimization studies.

Importantly, the ratio of lysozyme to excipients used in the studied formulations was observed to inhibit recrystallization of mannitol and sucrose to a significant extent for both $\mathrm{SD}$ and SFD processes. A recrystallization exotherm is observed on the DSC profiles of pure SD sucrose (Figure 5) and SFD sucrose (data not shown), which is absent in the DSC profiles of all processed powders. Additionally, DVS profiles show no evidence of sucrose recrystallization at increasing humidity with the different particle processing methods. The inhibition of phase separation of sucrose is important for protein stability, as it has been previously determined that both sucrose and the protein must be in the same matrix for sucrose to exert a stabilizing effect. ${ }^{51}$ The F10SFD powder did exhibit evidence of phase separation on its XRD pattern, with peaks corresponding to unprocessed sucrose. Evidence of phase separation was not noted for the F10SD powder. The F10 formulation and the F2 formulation contain the highest level of sucrose ( $\sim 4 \%$ ). This again points to the conclusion that the SFD process as it is currently designed carries an upper limit on the percentage of excipients that can be incorporated into the formulation. The tendency of the SFD process to result in a higher occurrence of phase separation may be explained by the Leidenfrost effect, which slows the effective cooling rate of the droplets atomized into $\mathrm{LN}_{2} .{ }^{52}$ Hypothetically, the atomization of formulation droplets into $\mathrm{LN}_{2}$ should result in rapid cooling that inhibits crystal nucleation. However, direct contact of the warmer droplets with the much cooler $\mathrm{LN}_{2}$ results in rapid boiling of the $\mathrm{LN}_{2}$ surrounding the droplets and creates a nitrogen vapor blanket that impedes heat transfer and slows cooling. ${ }^{52,53}$ This delay in cooling rate can enable crystallization to occur. ${ }^{54}$ Phase separation of formulation components is a concern for the long-term stability of the protein. In a recent study by Moussa et al., ${ }^{55}$ it was determined that the partial crystallinity of mannitol in a spray dried $\operatorname{IgG} 1 \mathrm{mAb}$ formulation resulted in fewer interactions of the excipient with the protein and, subsequently, structural perturbation of IgG1. Though a detailed stability analysis was not performed, it is possible that phase separation of the processed SFD formulations used in this study could result in structural damage to labile proteins. To achieve a completely amorphous and likely more stable state for SFD powders in future studies, the usage of a cyrogenic medium that has a higher freezing point than $\mathrm{LN}_{2}$, such as isopentane, ${ }^{53}$ could be considered to reduce the Leidenfrost effect. Elimination of mannitol from the formulations may also be prudent, given its tendency toward partial crystallinity.

Both water content and mannitol content influenced the $T_{\mathrm{g}}$ of SD and SFD formulations, as would be expected based upon the Gordon-Taylor equation. ${ }^{56,57}$ The $T_{\mathrm{g}}$ of D-mannitol has been previously reported to be $12.6{ }^{\circ} \mathrm{C} .{ }^{50}$ Incorporation of mannitol in the formulations ( $\mathrm{F} 4$ and F6) subsequently resulted in decreases in $T_{\mathrm{g}}$ of the powders compared to formulations that did not contain mannitol. The effect of water as a plasticizer in amorphous matrices is also well-studied. ${ }^{56}$ The SFD powders appeared to be particularly prone to having a low $T_{\mathrm{g}}$, which may be explained by their higher surface area compared to the SD powders. A larger surface area presents more opportunities for water adsorption and uptake into the bulk material. F4SFD and F6SFD, both of which contain mannitol, exhibited the lowest $T_{\mathrm{g}}$ of all the formulations. The $T_{\mathrm{g}}$ is an important consideration in determining appropriate storage temperature for a drug product, as storage near or above the $T_{\mathrm{g}}$ increases molecular 
mobility ${ }^{58}$ and would likely reduce the stabilizing effects on the protein incurred by the glassy state. ${ }^{59}$ The ability to store a respirable biologic powder at ambient temperatures is a desirable attribute; to achieve this, future optimization studies will consider the removal of mannitol from the formulation and additional drying steps to further increase powder $T_{\mathrm{g}}$.

Accumulation of protein at the air-liquid interface during processing may lead to unfolding and aggregation. ${ }^{60,61}$ The occurrence of protein surface accumulation for spray drying and spray freezing drying processes was compared using XPS. Despite all formulations containing equivalent levels of surfactant, SFD powders exhibited a lower percentage of excess surface protein compared to SD powders when the values were normalized to the $\mathrm{SA} / V$ ratio. For SD powders, excess surface protein was related to the concentration of lysozyme in the liquid preformulation. Ten percent solid content formulations (F2 and F4) exhibited a higher surface excess than 1\% solid content formulations (F6 and F10). The tendency for surface accumulation to occur with the SD process can be related to the Peclet number, which is the ratio of evaporation rate of the droplet to material diffusion into the core of the forming particle. ${ }^{13}$ The higher degree of surface protein excess for F2SD and F4SD points to saturation of the surface lysozyme; that is, a higher Peclet number for the formulation. The SFD process, in contrast, does not incorporate a rapid evaporation step, which can explain the lower surface accumulation in F2SFD and F4SFD powders. For formulations in which a high protein concentration is required, utilization of the SFD process may result in a more stable product.

\subsection{Spray Drying and Spray Freeze-Drying Processes Produce Powders with Differing Properties Relevant to Aerosol Performance.}

Aerodynamic performance and successful lung deposition of a respirable powder is highly dependent upon the individual particle and bulk powder properties, ${ }^{62,63}$ particularly particle size, density, powder flowability, and surface interactive forces ${ }^{64} \mathrm{SD}$ and SFD powders exhibited vastly different physicochemical characteristics. SD powders exhibited a smaller geometric PSD compared to SFD powders, though increasing the powder dispersion force resulted in a greater magnitude of decrease for the size distribution of SFD powders. From the standpoint of geometric PSD, the F6SD and F10SD powders (corresponding to a 1\% w/v solid content in the liquid feed) appeared most aptly suited for lung deposition. Despite their larger geometric PSD, the SFD powders exhibited a lower bulk and tapped density, which could lead to smaller aerodynamic diameter than would be inferred based solely upon their geometric PSD. The ability of the SFD process to generate low density powders makes it aptly suited for processing of highly concentrated powders, which would be more prone to both a larger PSD and a larger density if processed via spray drying.

Both SD and SFD processes produced particles with wrinkled surfaces, though for SD particles, the asperities were much larger. The presence of large hollows in the surface of SD particles enabled smaller particles to fit into the dented surface of larger particles, as noted on the SEM images. This could contribute to increased cohesiveness of the SD powders and reduced dispersibility through the process of mechanical interlocking. ${ }^{65}$ Surface area differences between particles produced with either of the two processes could also contribute to potential differences in aerosol performance, as the increased surface area could provide 
more opportunities for particle-particle interaction. Additionally, the larger specific surface area of SFD powders resulted in a higher rate of water uptake, which could introduce longterm stability problems, particularly for powders that have a low $T_{\mathrm{g}}$.

It is interesting to note that despite some of the produced powders having characteristics that would typically be highly favorable to deep lung deposition, such as geometric particle size of less than $3 \mu \mathrm{m}$ and low powder density, the aerosol metrics generated from the cascade impactions studies were lower than expected. Almost all of the processed powders dispersed from both the Handihaler and RS01-HR devices exhibited DDE values less than 50\%, which points to the inability of the devices to overcome the strong cohesive forces between particles. The devices used in this study and many of the generic DPI devices currently in development were designed to disperse carrier-based formulations. Given that the excipients incorporated in these formulations may be necessary to maintain the structural stability and activity of the protein, additional efforts may be required to engineer novel devices capable of dispersing these highly cohesive powders.

\subsection{Device-Powder Pairing and Formulation Composition Affects Aerosol Performance of SD and SFD Powders.}

Aerosol performance of the SD and SFD powders varied according to the DPI utilized. For every formulation except F2SD, the use of the RS01-HR device resulted in a higher DDE value than the Handihaler device, indicating the superior ability of the RS01-HR to fully disperse the powders utilized in the study. Though trends between devices differed, differences in aerosol performance between SD and SFD powders of the same formulation within the same device were in most cases statistically insignificant, despite significant differences in powder characteristics. In the Handihaler device, only the F6 formulation (containing 1\% total solids and 10\% mannitol in the initial liquid preformulation) exhibited a statistically significant difference in performance metrics, with the SFD powder exhibiting a much higher RF than the SD powder. No significant differences in RF were noted between the processing methods when the RS01-HR device was used. This finding underpins the importance of robust formulation design and supports the conclusion that the processing method is only as good as the underlying formulation.

MLR analysis performed on the powder characterization and aerosol performance data revealed that for each device the impact of powder properties on aerosol performance differed. While definitive conclusions cannot be drawn from the models given the size of the data set and the lack of statistically significant differences in powder aerosol performance, the general trends noted in the relationship between powder properties and aerosol performance using a particular device provides a useful starting point for the next phase of process and formulation optimization. Perhaps most notable is the effect of geometric particle size on the aerosol performance, which was inversed for the two devices tested. MLR analysis indicated that, when the powders were actuated using the Handihaler device, a smaller geometric particle diameter resulted in a reduction of DDE as well as EF. The powders with the smallest PSD (F6SD and F10SD) exhibited an increased deposition in the induction port and stage 1 area of the NGI apparatus when dispersed with the Handihaler device, indicating that complete deagglomeration did not occur. Interestingly, the EF of the 
F6SD and F10SD powders dispersed from the Handihaler device was not significantly lower than the other powders tested, which indicates that the size of the agglomerates is sufficient to enable fluidization and emission from the device. This is reflected in the MLR model for EF in the Handihaler device in which increasing Dv90 leads to increases in EF.

The $T_{\mathrm{g}}$ of the powders was also found to contribute to the efficiency of dispersion in the Handihaler device, as well as the aerosol performance (represented by $\mathrm{RF}_{<5 \mu \mathrm{m}}$ ) as determined by the statistical model. The $T_{\mathrm{g}}$ of a powder is known to influence its "stickypoint", a temperature and moisture content at which plastic deformation and increased cohesiveness of particles begin to occur. ${ }^{66,67}$ In this study, cascade impaction tests were performed at room temperature after a $30 \mathrm{~min}$ powder-in-capsule equilibration period for each powder, which may have negatively influenced the performance of powders with a $T_{\mathrm{g}}$ below $25^{\circ} \mathrm{C}$. The $T_{\mathrm{g}}$ of the F6SD powder was lower than that of any other SD powder, which may explain why its reduced aerosol. Due to its relationship with powder water content, the $T_{\mathrm{g}}$ is also heavily influenced by environmental conditions such as humidity. This may explain the poorer fit of the Handihaler model, as humidity was not controlled during the cascade impaction studies.

Particle size did not have a significant effect on the RF in the Handihaler device; instead, this metric was influenced by powder rugosity, $T_{\mathrm{g}}$, and tapped density. The dependency on rugosity to promote full deagglomeration and a high RF further points to the conclusion that Handihaler performance is greatly influenced by the cohesive forces between particles. A higher rugosity index (meaning that particles will exhibit a more wrinkled, rough surface) reduces the degree of contact between particles to only the diameter of the asperities, which will in turn decrease the magnitude of van der Waals cohesive forces ${ }^{64}$ according to eq 7 , where $d_{1}$ and $d_{2}$ indicated the diameter of the contact area between the two particles.

$$
F_{\mathrm{vdW}}=\frac{A}{6 h^{2}} \frac{d_{1} d_{2}}{d_{1}+d_{2}}
$$

In the RS01-HR device, decreasing particle size improved DDE and RF indicating that the impaction-based dispersion mechanism predominate in this device was better able to overcome cohesive particle forces in the powders tested compared to the shear-based dispersion mechanism of the Handihaler. Decreasing the density of the powder also improved aerosol performance metrics in the RS01-HR device based upon its effects on decreased aerodynamic diameter. Similar to trends noted for the Handihaler device, the influence of particle rugosity and $T_{\mathrm{g}}$ is noted in the model. The RS01-HR MLR model for $\mathrm{RF}_{<5 \mu \mathrm{m}}$ contained an additional surface-related parameter that was not found in the Handihaler model. For the RS01, the amount of excess lysozyme on the surface of the particle was inversely proportional to the $\mathrm{RF}_{<5 \mu \mathrm{m}}$. Increasing amounts of surface lysozyme may provide more opportunities for weak noncovalent interactions between particles as a 
result of amino acid residue exposure ${ }^{68}$ The MLR model indicates in the powders studied that particles agglomerated as a result of these interactions may be more easily dispersed using shear-based forces than impaction-based forces.

The MLR models presented are limited by the amount of data available for the analysis and should not be applied to make definitive predictions for other respirable biologic powders without further study and refinement. However, the regression analysis provides a useful way to summarize the trends noted in this particular data set, and the relationships noted in the models for each device provide a good basis for further formulation and process development. For example, some variables ( $T_{\mathrm{g}}$, rugosity, and powder density) were noted to be present in both the models for the Handihaler device and the RS01-HR device. This points to the importance of these particular powder characteristics in generating a robust formulation that can be dispersed using a variety of devices and will provide an important starting point for further optimization of respirable biologic powders. In the future, these models could provide an important tool for fast-screening of powder and device combinations through continual refinement with additional inputted data from powders of varying properties and devices with different dispersion mechanisms.

\section{CONCLUSION}

Spray drying and spray freeze-drying resulted in powders of varying characteristics, which in turn affects appropriate device selection and potentially long-term protein stability. Spray freeze-drying produced large, low density particles with high rugosity and surface area. Spray drying produced smaller, denser particles. Despite different properties, few significant differences existed in the aerosol performance of formulations produced by spray drying versus spray freeze-drying, which pointed to the robustness of the formulation. Multiple linear regression analysis was used to construct a model to identify trends in the data. Based on the model, the performance of large, low-density particles exhibited less dependency on the dispersion mechanism in the device compared to small, dense particles. Density, size distribution, rugosity, and glass transition temperature were important properties for performance in both devices tested. Lysozyme aggregation did not occur with either process; however, potential stability concerns exist with both processing methods based upon the properties of the resulting powders. The large surface area of SFD powders leads to greater water uptake, which makes this process inappropriate for formulations with a low $T_{\mathrm{g}}$. SD powders had a lower specific surface area, but higher amounts of protein surface accumulation, particularly for formulations with a higher concentration of protein in the liquid preformulation. This screening study, which examined the effect of the particle formation process on powder characteristics and aerosol performance using a variety of formulations, provides an important foundation for additional optimization of biologic DPIs. By subjecting template formulations containing many commonly used excipients in solidstate biopharmaceutical manufacturing to two highly relevant particle engineering processes, the findings of this study contribute to further understanding the limits of the biologic DPI design space. The next phase of our study, which will utilize a more labile mAb molecule and extensive analysis of the processing effects on structure and activity, will provide additional guidance on the most appropriate particle formation method to ensure long-term stability and improved aerosol performance of respirable biopharmaceutical powders. 


\section{Supplementary Material}

Refer to Web version on PubMed Central for supplementary material.

\section{ACKNOWLEDGMENTS}

The authors are thankful to members of the Smyth lab (University of Texas at Austin) for their valuable feedback on this manuscript, and to Dr. Hugo Ceilo at the University of Texas at Austin, Texas Materials Institute for his assistance with the XPS experiments. Research reported in this publication is supported by Amgen Inc., and in part by a Graduate Student Fellowship Award from the American Association of Pharmaceutical Scientists Foundation. Additional research support was provided by the National Heart, Lung, and Blood Institute of the National Institutes of Health under Award Number F31HL146178. The content reported herein is solely the responsibility of the authors and does not necessarily represent the official views of the National Institutes of Health.

\section{ABBREVIATIONS}

SD

SFD

DPI

SSA

DoE

LN2

PSD

SEM

RI

CI

TGA

DSC

XRD

DVS

XPS

NGI

RS01-HR

MOC

EF

$\mathbf{R F}_{<5 \mu \mathrm{m}}$

$\mathbf{R F}_{<3 \mu \mathrm{m}}$ spray dried

spray freeze-dried

dry powder inhaler

specific surface area

design of experiments

liquid nitrogen

particle size distribution

scanning electron microscopy

rugosity index

compressibility index

thermogravimetric analysis

differential scanning calorimetry

X-ray powder diffraction

dynamic vapor sorption

X-ray photoelectron spectroscopy

Next Generation Impactor

RS01-high resistanc

micro-orifice collector

emitted fraction

respirable fraction ( $5 \mu \mathrm{m}$ cutoff)

respirable fraction ( $3 \mu \mathrm{m}$ cutoff) 


$\begin{array}{ll}\text { MMAD } & \text { mass median aerodynamic diameter } \\ \text { GSD } & \text { geometric standard deviation } \\ \text { DE } & \text { deagglomeration efficiency } \\ \boldsymbol{d}_{\text {geo }} & \text { geometric diameter } \\ \boldsymbol{d}_{\mathbf{a e}} & \text { aerodynamic diameter } \\ \text { MLR } & \text { multiple linear regression } \\ \text { VIF } & \text { variance inflation factor } \\ \boldsymbol{T}_{\mathbf{g}} & \text { glass transition temperature } \\ \text { SEC } & \text { size exclusion chromatography }\end{array}$

\section{REFERENCES}

(1). Fröhlich E; Mercuri A; Wu S; Salar-Behzadi S Measurements of Deposition, Lung Surface Area and Lung Fluid for Simulation of Inhaled Compounds. Front. Pharmacol 2016, 7, 181. [PubMed: 27445817]

(2). Guillon A; Pardessus J; Lhommet P; Parent C; Respaud R; Marchand D; Montharu J; De Monte M; Janiak P; Boixel C Exploring the fate of inhaled monoclonal antibody in the lung parenchyma by microdialysis. mAbs 2019, 11, 1-8. [PubMed: 30303443]

(3). Guilleminault L; Azzopardi N; Arnoult C; Sobilo J; Herve V; Montharu J; Guillon A; Andres C; Herault O; Le Pape A; Diot P; Lemarié E; Paintaud G; Gouilleux-Gruart V; Heuzé-Vourc'h N Fate of inhaled monoclonal antibodies after the deposition of aerosolized particles in the respiratory system. J. Controlled Release 2014, 196, 344-354.

(4). Rahhal TB; Fromen CA; Wilson EM; Kai MP; Shen TW; Luft JC; DeSimone JM Pulmonary Delivery of Butyrylcholinesterase as a Model Protein to the Lung. Mol. Pharmaceutics 2016, 13 (5), 1626-1635.

(5). Topp EM; Zhang L; Zhao H; Payne RW; Evans GJ; Manning MC Chemical Instability in Peptide and Protein Pharmaceuticals; John Wiley \& Sons, Inc.: Hoboken, NJ, 2010.

(6). Maa Y-F; Prestrelski S Biopharmaceutical Powders Particle Formation and Formulation Considerations. Curr. Pharm. Biotechnol 2000, 1 (3), 283-302. [PubMed: 11469385]

(7). Maa Y-F; Nguyen P-A; Sweeney T; Shire SJ; Hsu CC Protein Inhalation Powders: Spray Drying vs Spray Freeze Drying. Pharm. Res 1999, 16 (2), 249-254. [PubMed: 10100310]

(8). Ledet GA; Graves RA; Bostanian LA; Mandal TK Spray-Drying of Biopharmaceuticals In Lyophilized Biologics and Vaccines: Modality-Based Approaches; Varshney D, Singh M, Eds.; Springer New York: New York, 2015; pp 273-297.

(9). White S; Bennett DB; Cheu S; Conley PW; Guzek DB; Gray S; Howard J; Malcolmson R; Parker JM; Roberts P; Sadrzadeh N; Schumacher JD; Seshadri S; Sluggett GW; Stevenson CL; Harper NJ EXUBERA®: Pharmaceutical Development of a Novel Product for Pulmonary Delivery of Insulin. Diabetes Technol. Ther 2005, 7 (6), 896-906. [PubMed: 16386095]

(10). Cal K; Sollohub K Spray drying technique. I: Hardware and process parameters. J. Pharm. Sci 2010, 99, 575-86. [PubMed: 19774644]

(11). Schule S; Schulz-Fademrecht T; Garidel P; Bechtold-Peters K; Fries W Stabilization of IgG1 in spray-dried powders for inhalation. Eur. J. Pharm. Biopharm 2008, 69 (3), 793-807. [PubMed: 18477504]

(12). Cal K; Sollohub K Spray Drying Technique. I: Hardware and Process Parameters. J. Pharm. Sci 2010, 99 (2), 575-586. [PubMed: 19774644]

(13). Vehring R Pharmaceutical particle engineering via spray drying. Pharm. Res 2008, 25, 999-1022. [PubMed: 18040761] 
(14). Yu Z; Johnston KP; Williams RO Spray freezing into liquid versus spray-freeze drying: Influence of atomization on protein aggregation and biological activity. Eur. J. Pharm. Sci 2006, 27 (1), 918. [PubMed: 16188431]

(15). Kasper JC; Friess W The freezing step in lyophilization: physico-chemical fundamentals, freezing methods and consequences on process performance and quality attributes of biopharmaceuticals. Eur. J. Pharm. Biopharm 2011, 78 (2), 248-63. [PubMed: 21426937]

(16). Wanning S; Süverkrüp R; Lamprecht A Pharmaceutical spray freeze drying. Int. J. Pharm 2015, 488 (1), 136-153. [PubMed: 25900097]

(17). Costantino HR; Firouzabadian L; Hogeland K; Wu C; Beganski C; Carrasquillo KG; Córdova M; Griebenow K; Zale SE; Tracy MA Protein Spray-Freeze Drying. Effect of Atomization Conditions on Particle Size and Stability. Pharm. Res 2000, 17 (11), 1374-1382. [PubMed: 11205730]

(18). Costantino HR; Firouzabadian L; Wu C; Carrasquillo KG ; Griebenow K; Zale SE; Tracy MA Protein spray freeze drying. 2. Effect of formulation variables on particle size and stability. J. Pharm. Sci 2002, 91 (2), 388-395. [PubMed: 11835198]

(19). Nguyen XC; Herberger JD; Burke PA Protein Powders for Encapsulation: A Comparison of Spray-Freeze Drying and Spray Drying of Darbepoetin Alfa. Pharm. Res 2004, 21 (3), 507-514. [PubMed: 15070103]

(20). Saluja V; Amorij JP; Kapteyn JC; de Boer AH; Frijlink HW; Hinrichs WL A comparison between spray drying and spray freeze drying to produce an influenza subunit vaccine powder for inhalation. J. Controlled Release 2010, 144 (2), 127-33.

(21). Ferrati S; Wu T; Fuentes O; Brunaugh AD; Kanapuram SR; Smyth HDC Influence of Formulation Factors on the Aerosol Performance and Stability of Lysozyme Powders: a Systematic Approach. AAPS PharmSciTech 2018, 19, 2755. [PubMed: 29488193]

(22). Donovan MJ; Kim SH; Raman V; Smyth HD Dry Powder Inhaler Device Influence on Carrier Particle Performance. J. Pharm. Sci 2012, 101 (3), 1097-1107. [PubMed: 22095397]

(23). Zhou Q; Tang P; Leung SSY; Chan JGY; Chan H-K Emerging inhalation aerosol devices and strategies: Where are we headed? Adv. Drug Delivery Rev 2014, 75, 3-17.

(24). Vidgren M; Kärkkäinen A; Karjalainen P; Paronen P; Nuutinen J Effect of powder inhaler design on drug deposition in the respiratory tract. Int. J. Pharm 1988, 42 (1-3), 211-216.

(25). Ziaee A; Albadarin AB; Padrela L; Femmer T; O’Reilly E; Walker G Spray drying of pharmaceuticals and biopharmaceuticals: Critical parameters and experimental process optimization approaches. Eur. J. Pharm. Sci 2019, 127, 300-318. [PubMed: 30428336]

(26). Jaffari S; Forbes B; Collins E; Barlow DJ; Martin GP; Murnane D Rapid characterisation of the inherent dispersibility of respirable powders using dry dispersion laser diffraction. Int. J. Pharm 2013, 447, 124-131. [PubMed: 23434542]

(27). Costantino HR; Curley JG; Wu S; Hsu CC Water sorption behavior of lyophilized protein-sugar systems and implications for solid-state interactions. Int. J. Pharm 1998, 166 (2), 211-221.

(28). Hsu CC; Ward CA; Pearlman R; Nguyen HM; Yeung DA; Curley JG Determining the optimum residual moisture in lyophilized protein pharmaceuticals. Dev. Biol. Stand 1992, 74, 255-70. [PubMed: 1592175]

(29). Elkins MR; Anderson SD; Perry CP; Daviskas E; Charlton B Inspiratory flows and volumes in subjects with non-CF bronchiectasis using a new dry powder inhaler device. Open Respir. Med. J 2014, 8, 8. [PubMed: 24570764]

(30). Physical tests and determinations: inhalation and nasal drug products: aerosols, sprays, and powders-performance quality tests In United States Pharrmacopeia and National Formulary (USP 39-NF 34); United States Pharmacopeial Convention: Rockville, MD, 2016; pp 423-449.

(31). Marple VA; Olson BA; Santhanakrishnan K; Mitchell JP; Murray SC; Hudson-Curtis BL Next generation pharmaceutical impactor (a new impactor for pharmaceutical inhaler testing). Part II: Archival calibration. J. Aerosol Med 2003, 16 (3), 301-324. [PubMed: 14572327]

(32). Brunaugh AD; Smyth HD Formulation techniques for high dose dry powders. Int. J. Pharm 2018, 547 (1-2), 489-498. [PubMed: 29778822]

(33). R Core Team. R: A Language and Environment for Statistical Computing; R Foundation for Statistical Computing: Vienna, 2019. 
(34). Shamblin SL; Hancock BC; Zografi G Water vapor sorption by peptides, proteins and their formulations. Eur. J. Pharm. Biopharm 1998, 45 (3), 239-247. [PubMed: 9653628]

(35). Imamura K; Maruyama Y; Tanaka K; Yokoyama T; Imanaka H; Nakanishi K True density analysis of a freeze-dried amorphous sugar matrix. J. Pharm. Sci 2008, 97 (7), 2789-2797. [PubMed: 17918722]

(36). van den Dries IJ; van Dusschoten D; Hemminga MA; van der Linden E Effects of Water Content and Molecular Weight on Spin Probe and Water Mobility in Malto-oligomer Glasses. J. Phys. Chem. B 2000, 104 (44), 10126-10132.

(37). Crowder TM A Guide to Pharmaceutical Particulate Science; Interpharm Press/CRC: 2003.

(38). <1174> Powder Flow In United States Pharmacopeia and National Formulary (USP 41-NF 36); United States Pharmacopeial Convention: Rockville, MD, 2018; p 7481.

(39). Nunes C; Suryanarayanan R; Botez CE; Stephens PW Characterization and Crystal Structure of D-Mannitol Hemihydrate. J. Pharm. Sci 2004, 93 (11), 2800-2809. [PubMed: 15368529]

(40). Roos YH; Karel M; Labuza TP; Levine H; Mathlouthi M; Reid D; Shalaev E; Slade L Melting and crystallization of sugars in high-solids systems. J. Agric. Food Chem 2013, 61 (13), 316778. [PubMed: 23470203]

(41). Lee JW; Thomas LC; Schmidt SJ Effects of heating conditions on the glass transition parameters of amorphous sucrose produced by melt-quenching. J. Agric. Food Chem 2011, 59 (7), 3311-9. [PubMed: 21381719]

(42). Weers JG; Miller DP Formulation Design of Dry Powders for Inhalation. J. Pharm. Sci 2015, 104 (10), 3259-88. [PubMed: 26296055]

(43). Carpenter JF; Pikal MJ; Chang BS; Randolph TW Rational Design of Stable Lyophilized Protein Formulations: Some Practical Advice. Pharm. Res 1997, 14 (8), 969-975. [PubMed: 9279875]

(44). Wang W Lyophilization and development of solid protein pharmaceuticals. Int. J. Pharm 2000, 203 (1), 1-60. [PubMed: 10967427]

(45). Mensink MA; Frijlink HW; van der Voort Maarschalk K; Hinrichs WL How sugars protect proteins in the solid state and during drying (review): Mechanisms of stabilization in relation to stress conditions. Eur. J. Pharm. Biopharm 2017, 114, 288-295. [PubMed: 28189621]

(46). Zbacnik TJ; Holcomb RE; Katayama DS; Murphy BM; Payne RW; Coccaro RC; Evans GJ; Matsuura JE; Henry CS; Manning MC Role of Buffers in Protein Formulations. J. Pharm. Sci 2017, 106 (3), 713-733. [PubMed: 27894967]

(47). Chang BS; Kendrick BS; Carpenter JF Surface-Induced Denaturation of Proteins during Freezing and its Inhibition by Surfactants. J. Pharm. Sci 1996, 85 (12), 1325-1330. [PubMed: 8961147]

(48). Izutsu K.-i.; Yoshioka S; Terao T Decreased Protein-Stabilizing Effects of Cryoprotectants Due to Crystallization. Pharm. Res 1993, 10 (8), 1232-1237. [PubMed: 8415413]

(49). Costantino HR; Andya JD; Nguyen P-A; Dasovich N; Sweeney TD; Shire SJ; Hsu CC; Maa Y-F Effect of mannitol crystallization on the stability and aerosol performance of a spray-dried pharmaceutical protein, recombinant humanized anti-IgE monoclonal antibody. J. Pharm. Sci 1998, 87 (11), 1406-1411. [PubMed: 9811498]

(50). Yu L; Mishra DS; Rigsbee DR Determination of the Glass Properties of D-Mannitol Using Sorbitol as an Impurity. J. Pharm. Sci 1998, 87 (6), 774-777. [PubMed: 9607958]

(51). Tzannis ST; Prestrelski SJ Moisture effects on Protein Excipient Interactions in Spray-dried Powders. Nature of Destabilizing effects of Sucrose. J. Pharm. Sci 1999, 88 (3), 360-370. [PubMed: 10052996]

(52). Song YS; Adler D; Xu F; Kayaalp E; Nureddin A; Anchan RM; Maas RL; Demirci U Vitrification and levitation of a liquid droplet on liquid nitrogen. Proc. Natl. Acad. Sci. U. S. A 2010, 107 (10), 4596-4600. [PubMed: 20176969]

(53). Engstrom JD; Simpson DT; Lai ES; Williams RO 3rd; Johnston KP Morphology of protein particles produced by spray freezing of concentrated solutions. Eur. J. Pharm. Biopharm 2007, 65 (2), 149-62. [PubMed: 17010582]

(54). Feng H; Xu Y; Yang T Study on Leidenfrost effect of cryoprotectant droplets on liquid nitrogen with IR imaging technology and non-isothermal crystallization kinetics model. Int. J. Heat Mass Transfer 2018, 127, 413-421. 
(55). Moussa EM; Wilson NE; Zhou QT; Singh SK; Nema S; Topp EM Effects of Drying Process on an IgG1Monoclonal Antibody Using Solid-State Hydrogen Deuterium Exchange with Mass Spectrometric Analysis (ssHDX-MS). Pharm. Res 2018, 35 (1), 12. [PubMed: 29299701]

(56). Hancock BC; Zografi G The Relationship Between the Glass Transition Temperature and the Water Content of Amorphous Pharmaceutical Solids. Pharm. Res 1994, 11 (4), 471-477. [PubMed: 8058600]

(57). Gordon M; Taylor JS Ideal copolymers and the second-order transitions of synthetic rubbers. i. non-crystalline copolymers. J. Appl. Chem 1952, 2 (9), 493-500.

(58). Hancock BC; Shamblin SL; Zografi G Molecular Mobility of Amorphous Pharmaceutical Solids Below Their Glass Transition Temperatures. Pharm. Res 1995, 12 (6), 799-806. [PubMed: 7667182]

(59). Lai MC; Topp EM Solid-state chemical stability of proteins and peptides. J. Pharm. Sci 1999, 88 (5), 489-500. [PubMed: 10229638]

(60). Maa Y-F; Nguyen P-AT; Hsu SW Spray-Drying of Air-Liquid Interface Sensitive Recombinant Human Growth Hormone. J. Pharm. Sci 1998, 87 (2), 152-159. [PubMed: 9519146]

(61). Webb SD; Golledge SL; Cleland JL; Carpenter JF; Randolph TW Surface adsorption of recombinant human interferon-gamma in lyophilized and spray-lyophilized formulations. J. Pharm. Sci 2002, 91 (6), 1474-87. [PubMed: 12115847]

(62). Hickey AJ; Mansour HM; Telko MJ; Xu Z; Smyth HD; Mulder T; McLean R; Langridge J; Papadopoulos D Physical characterization of component particles included in dry powder inhalers. I. Strategy review and static characteristics. J. Pharm. Sci 2007, 96 (5), 1282-1301. [PubMed: 17455324]

(63). Hickey AJ; Mansour HM; Telko MJ; Xu Z; Smyth HD; Mulder T; McLean R; Langridge J; Papadopoulos D Physical characterization of component particles included in dry powder inhalers. II. Dynamic characteristics. J. Pharm. Sci 2007, 96 (5), 1302-1319. [PubMed: 17455364]

(64). Donovan MJ; Gibbons A; Herpin MJ; Marek S; McGill SL; Smyth HDC Novel dry powder inhaler particle-dispersion systems. Ther. Delivery 2011, 2 (10), 1295.

(65). Telko MJ; Hickey AJ Dry Powder Inhaler Formulation. Respir. Care 2005, 50 (9), 1209. [PubMed: 16122404]

(66). Downton GE; Flores-Luna JL; King CJ Mechanism of stickiness in hygroscopic, amorphous powders. Ind. Eng. Chem. Fundam 1982, 21 (4), 447-451.

(67). Ozmen L; Langrish TAG COMPARISON OF GLASS TRANSITION TEMPERATURE AND STICKY POINT TEMPERATURE FOR SKIM MILK POWDER. Drying Technol 2002, 20 (6), 1177.

(68). Gray JJ The interaction of proteins with solid surfaces. Curr. Opin. Struct. Biol 2004, 14 (1), 110-115. [PubMed: 15102457] 
A
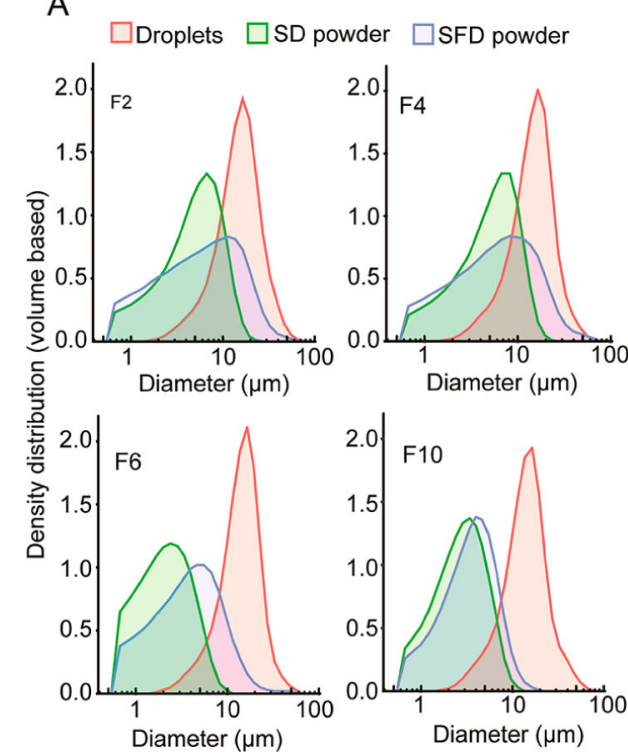

B

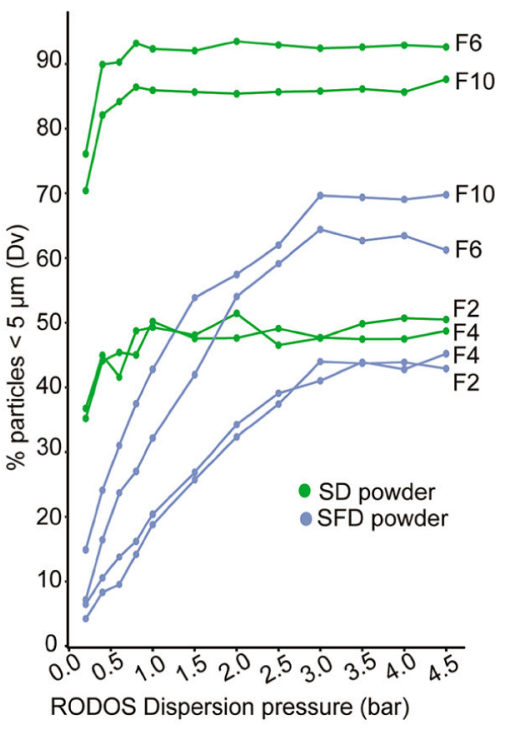

Figure 1.

SD and SFD processes have varying effects on particle size distribution (A) and powder dispersion profile (B) for the formulations tested. Powders with $10 \%$ solid content in the initial liquid feed (F2 and F4) exhibit a larger median diameter than powders with $1 \%$ solid content (F6 and F10) for both processes. Complete dispersion of SD powders is achieved at a lower dispersion energy compared to SFD powders. 


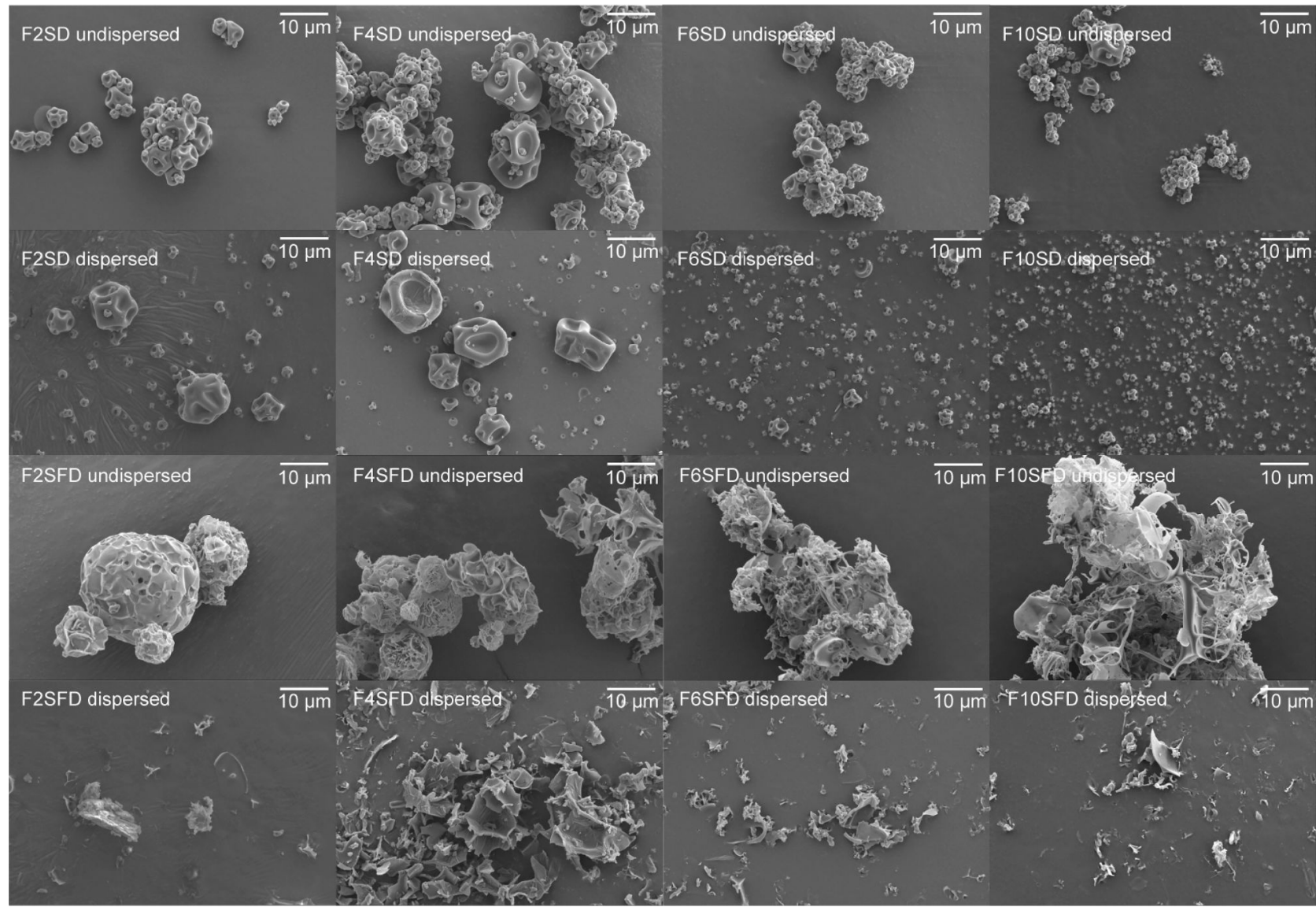

Figure 2.

SD particles exhibit uniform morphology despite formulation differences. Deagglomeration occurs via separation of individual particles. SFD particles exhibit agglomerate morphology that is dependent upon solid content in the liquid formulation (F2 and F4-10\%; F6 and F10$1 \%)$. Deagglomeration occurs by fracture of the powder matrix. 

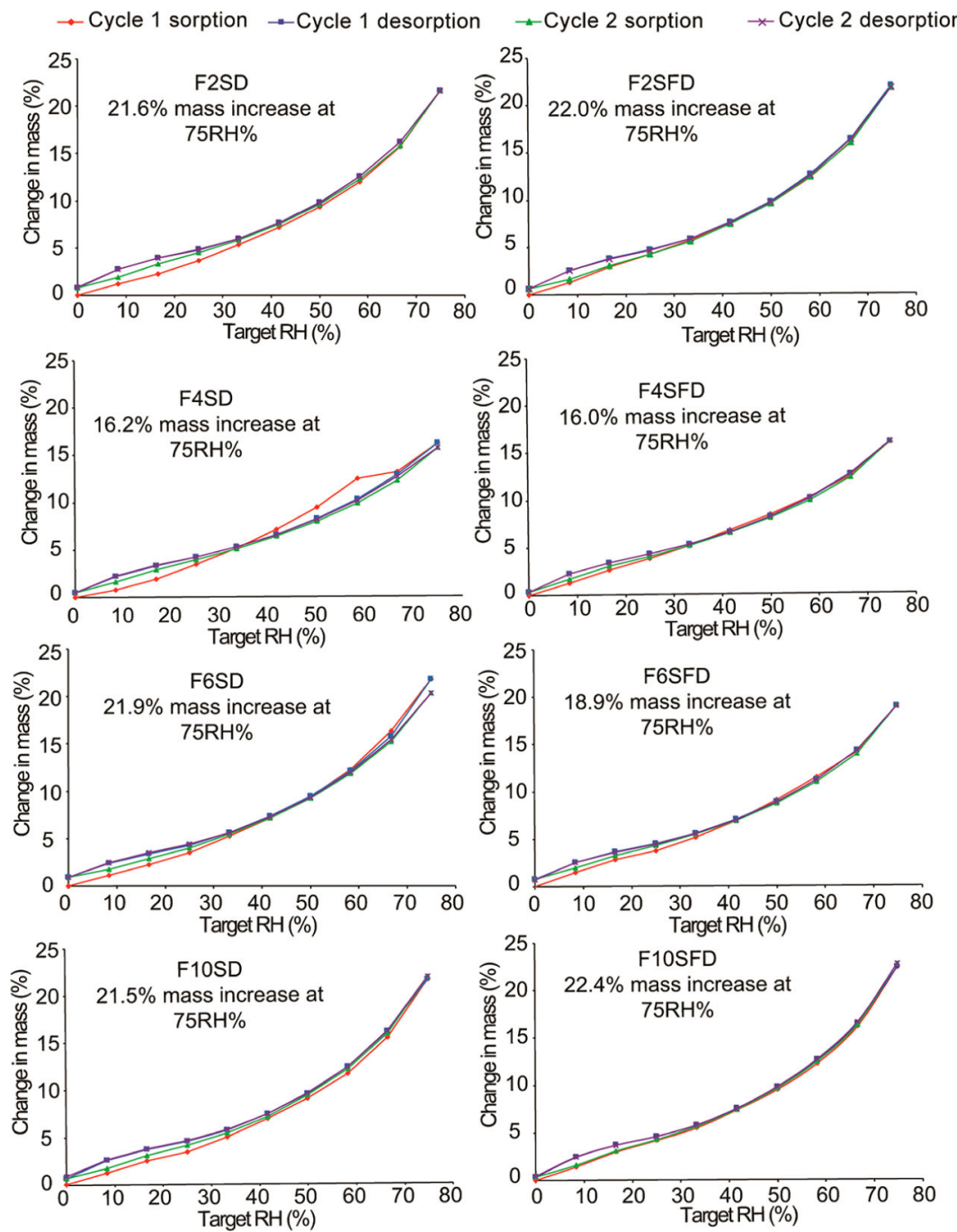

Figure 3.

DVS profiles of SD and SFD powders show formulations are highly hygroscopic and exhibit a type III isotherm with limited hysteresis. 

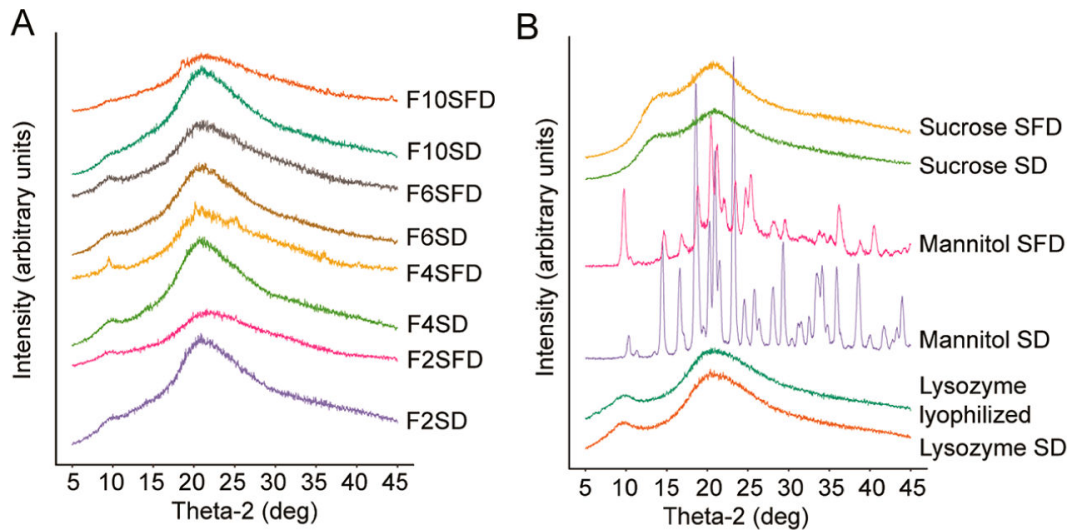

Figure 4.

(A) XRD reveals phase separation in SFD formulations (F4SFD and F10SFD). (B) XRD patterns of processed singular formulation components show crystallization of mannitol in both processes without the addition of sucrose and lysozyme. 

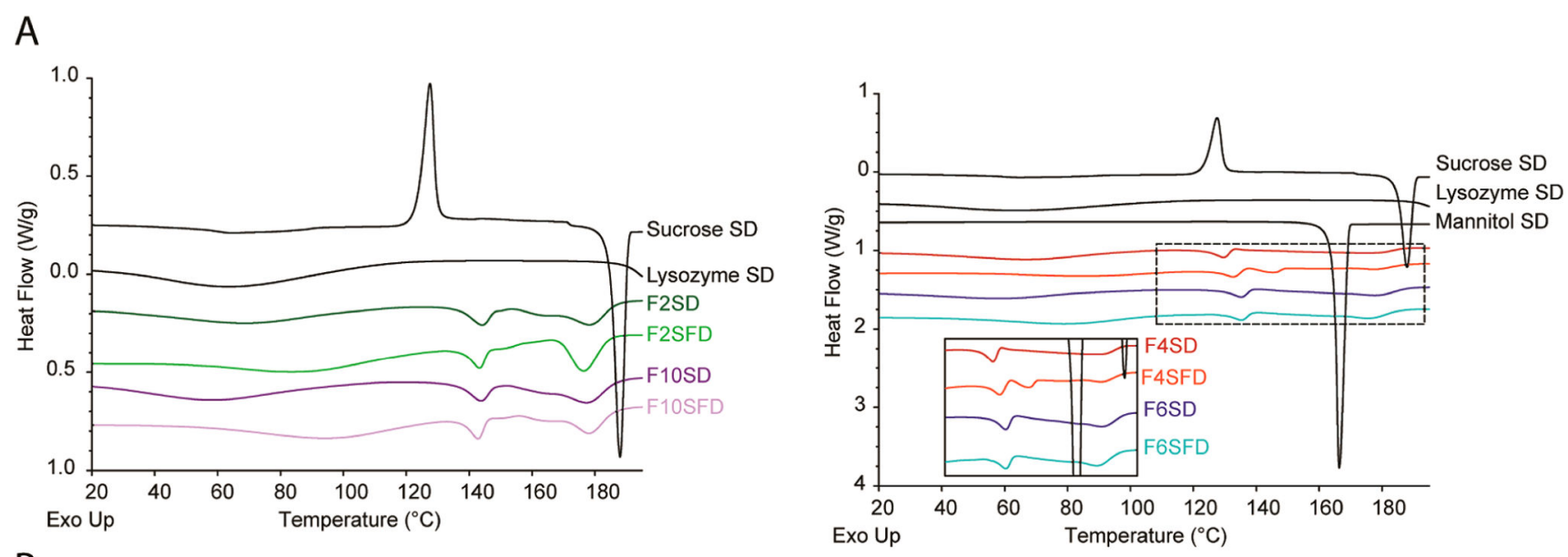

B
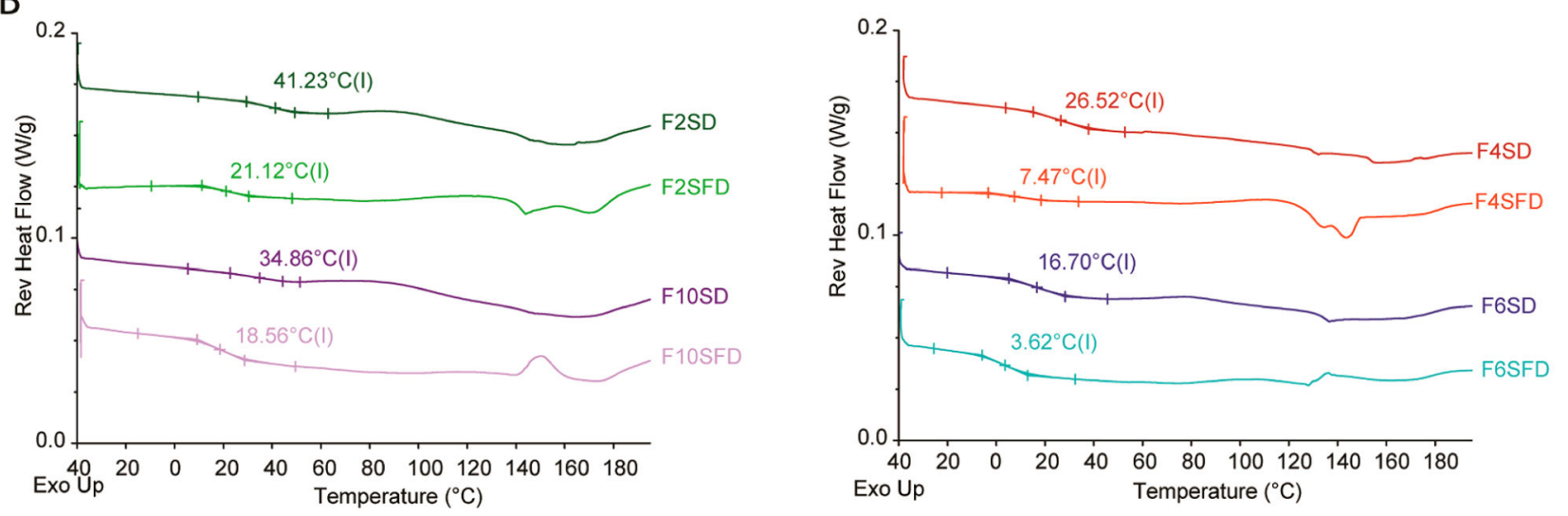

Figure 5.

(A) Total heat flow and (B) reverse heat flow DSC scans of SD and SFD formulations. For both drying processes, recrystallization of sucrose is inhibited. Presence of mannitol in the formulation (F4 and F6) results in a lowering of the $T_{\mathrm{g}}$. 
A.

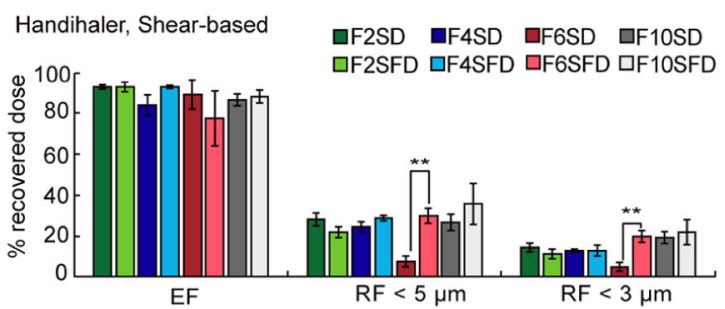

RS01, Impaction-based

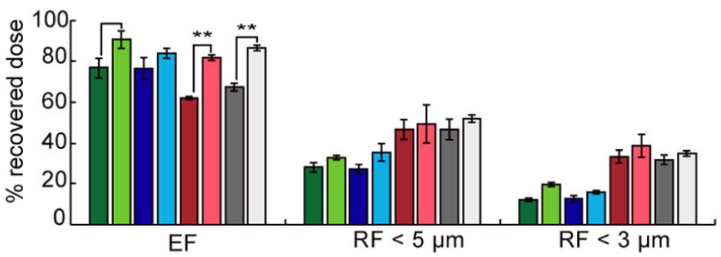

B.

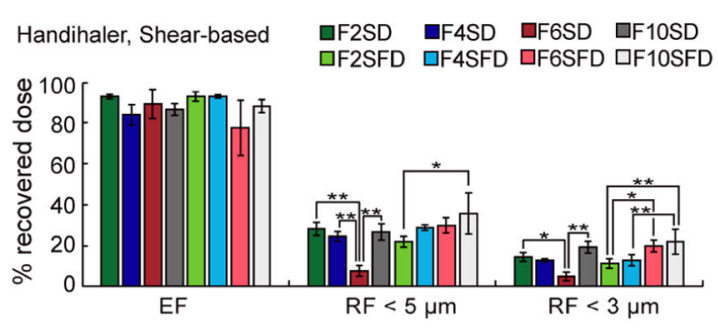

RS01, Impaction-based

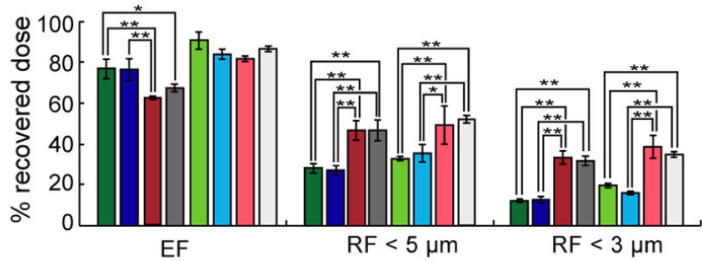

C.

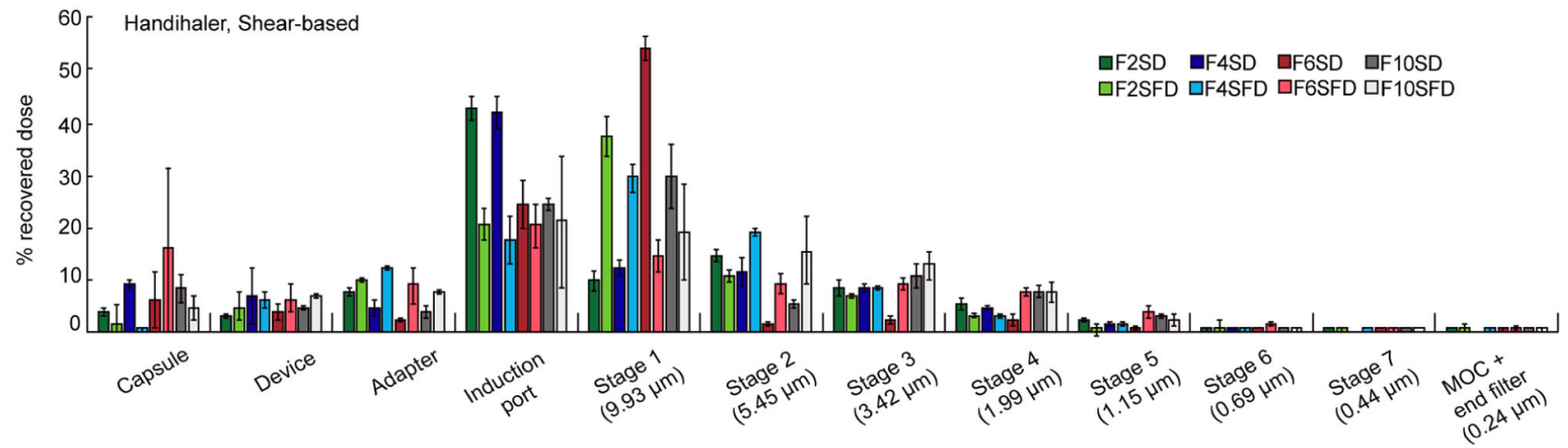

D.

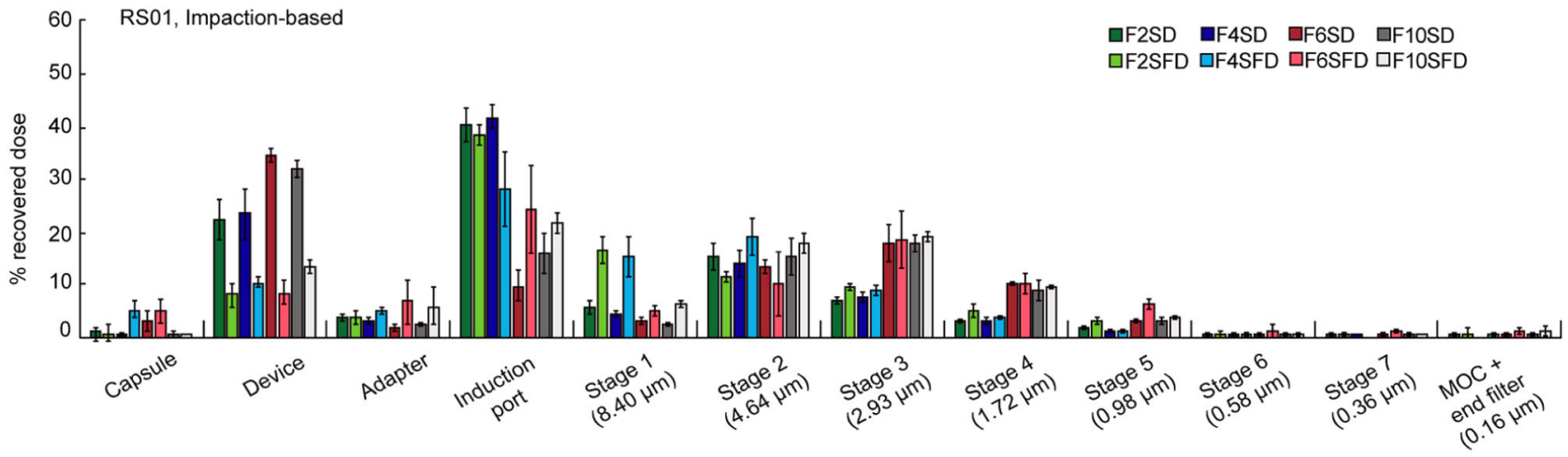

Figure 6.

Aerosol performance of powders generated from spray drying and spray freeze-drying processes differed according to the device used to disperse the powders. (A) Powders with the same formulation composition produced using different particle formation methods were compared. The particle formation process had a statistically significant effect on the RF of the F6 formulation in the Handihaler device and on the EF of powders in the RS01-HR device. (B) Powders produced with the same particle formation process but different formulation compositions were compared. Formulations made with $1 \%$ solids had a higher RF than formulations with 10\% solids in the RS01 device. (C) F6SD and F10SD exhibit a 
large portion of deposition in the induction port and stage 1 sections of the NGI when dispersed using the Handihaler device, which is shifted toward the later stages when dispersion occurs with the RS01-HR device (D). 
Table 1.

Composition of Formulations Used for Spray Drying and Spray Freeze Drying Processes

\begin{tabular}{ccccccc}
\hline Name & $\begin{array}{c}\text { \% w/v Solids in } \\
\text { liquid feed }\end{array}$ & \% w/w Lysozyme & \% w/w Sucrose & \% w/w D- Mannitol & \% w/w Histidine & \% w/w Polysorbate 80 \\
F2 & 10 & 58.81 & 39.21 & 0 & 1.74 \\
F4 & 10 & 58.81 & 19.60 & 19.60 & 1.74 \\
F6 & 1 & 58.81 & 29.41 & 9.80 & 0.24 \\
F10 & 1 & 58.81 & 39.21 & 0 & 1.74 & 0.24 \\
\hline
\end{tabular}




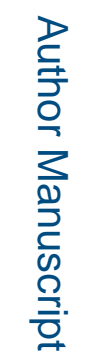

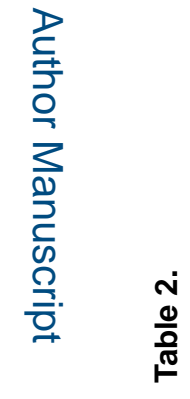

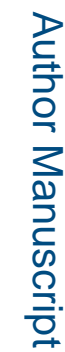

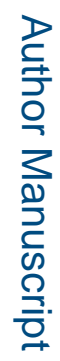

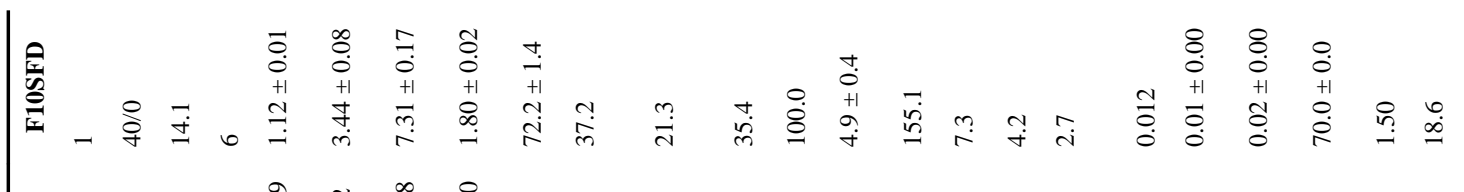

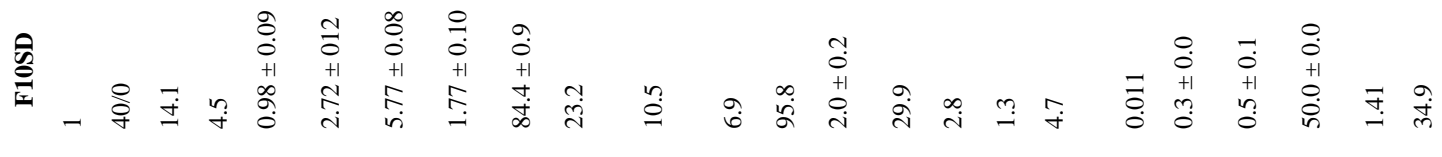

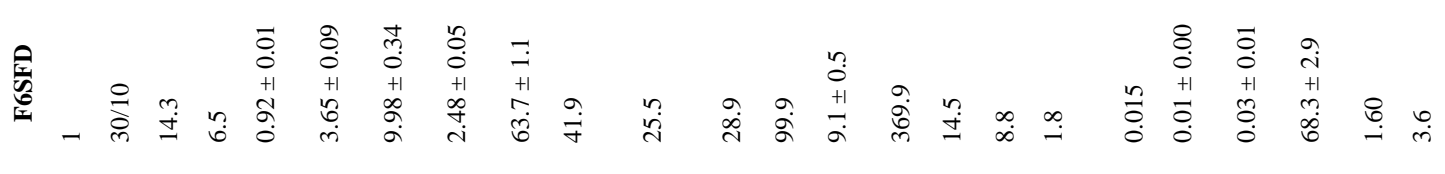

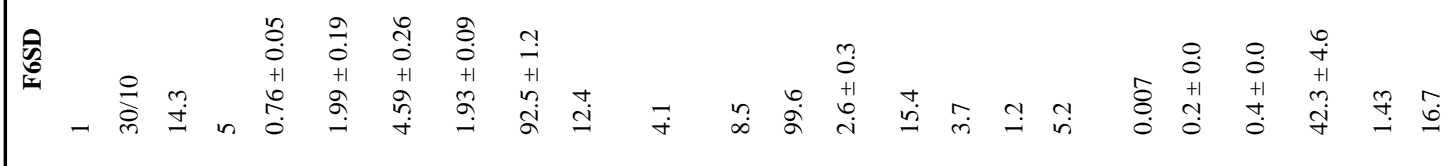

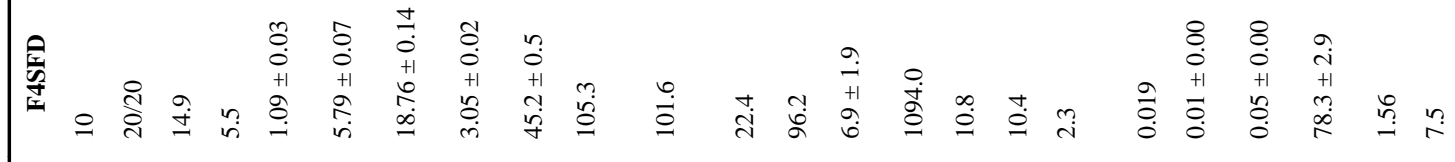

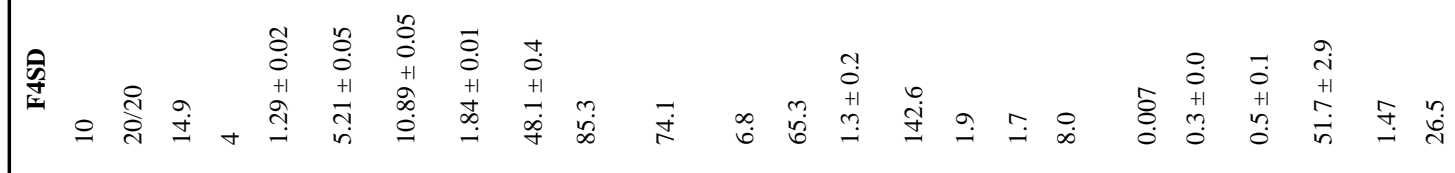

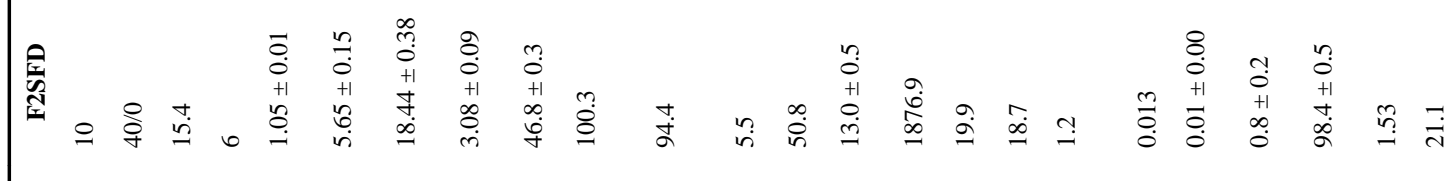

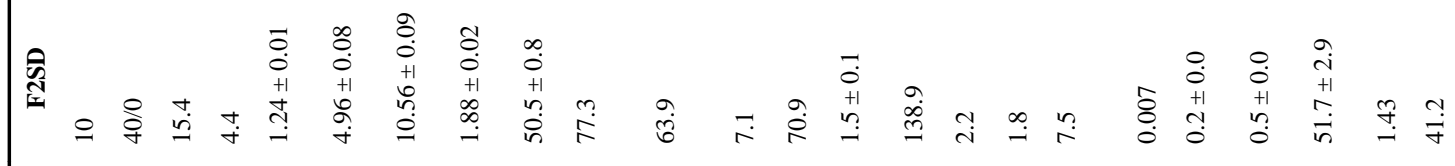

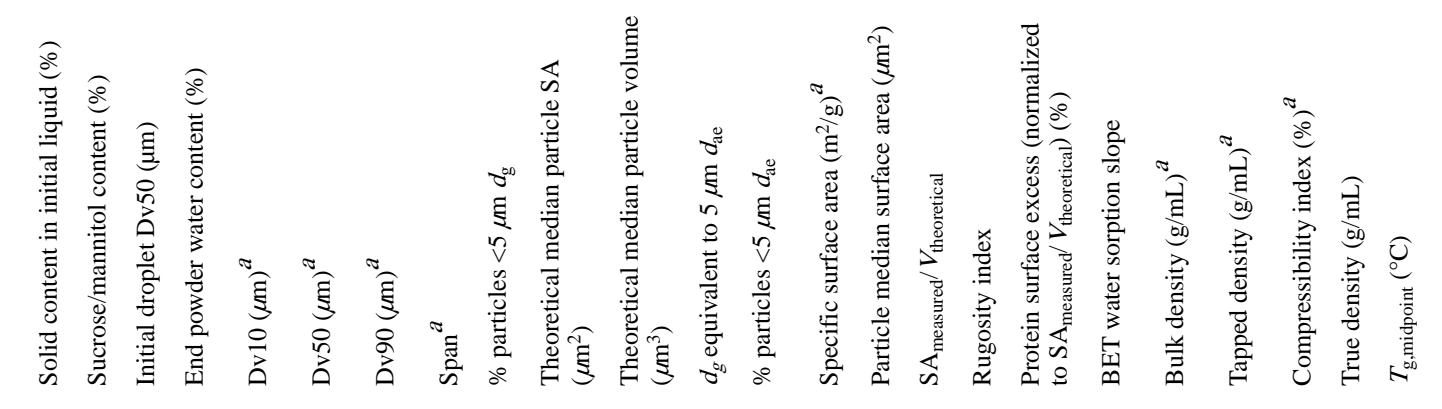
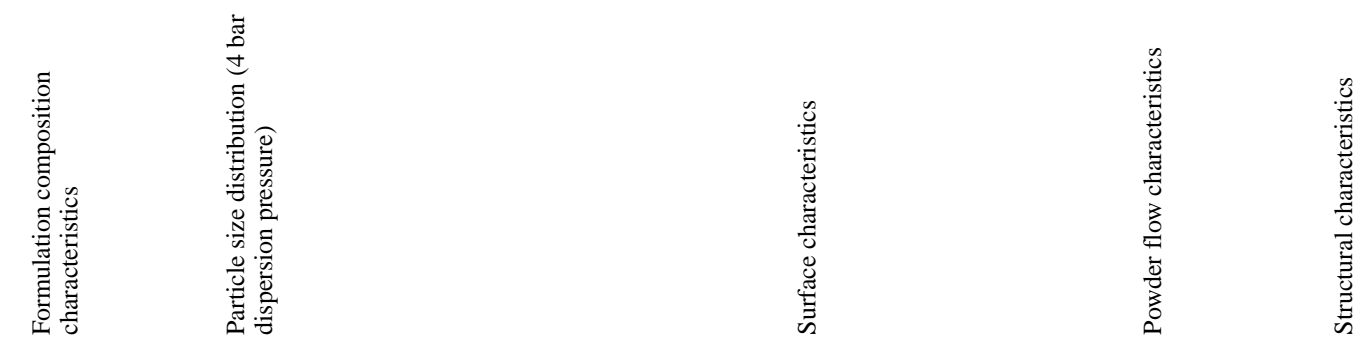

Mol Pharm. Author manuscript; available in PMC 2019 October 18. 
Brunaugh et al.

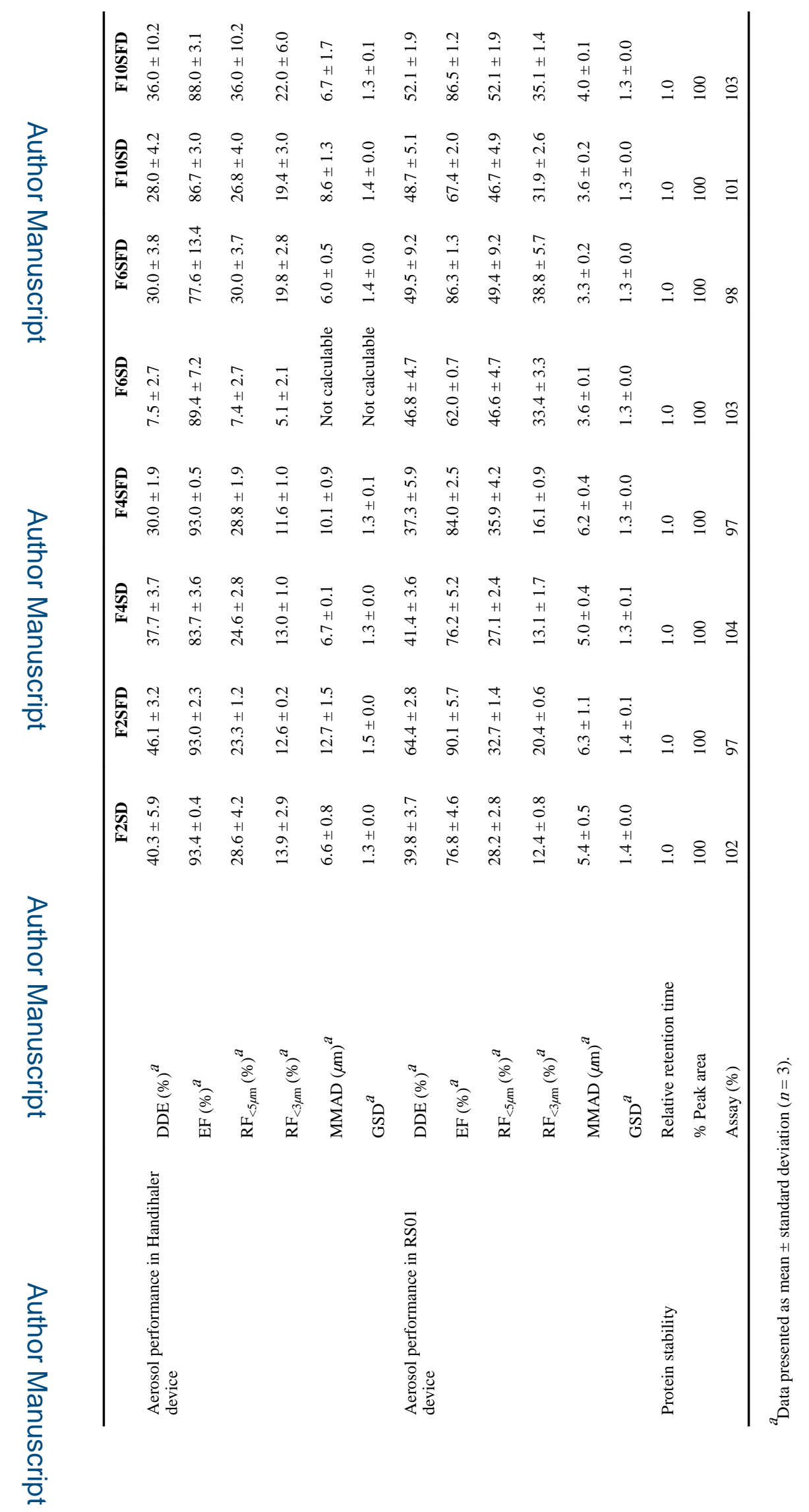

Mol Pharm. Author manuscript; available in PMC 2019 October 18. 
Table 3.

Models for Aerosol Performance in Handihaler and RS01 Devices

\begin{tabular}{lcl}
\hline \multicolumn{1}{c}{ Model $^{\boldsymbol{a}}$} & Adj $\boldsymbol{R}^{\mathbf{2}}$ & \multicolumn{1}{c}{$\boldsymbol{P}$-value } \\
$\mathrm{DDE}(\%)_{\mathrm{HH}}=1.56 \mathrm{Dv} 90_{4 \mathrm{bar}}+0.45 \mathrm{~T}_{\mathrm{g}}+5.66$ & 0.38 & 0.13 \\
$\mathrm{EF}(\%)_{\mathrm{HH}}=0.65 \mathrm{Dv} 90_{4 \mathrm{bar}}-5.83 \mathrm{Dv} 90_{0.2 \mathrm{bar}}+84.60$ & 0.55 & 0.06 \\
$\mathrm{RF}(\%)_{\mathrm{HH}}=1.33 \mathrm{RI}+0.90 \mathrm{~T}_{\mathrm{g}}-40.01 \rho_{\text {tapped }}+12.78$ & 0.44 & 0.17 \\
$\mathrm{DDE}(\%)_{\mathrm{RS} 01}=9.40 \rho_{\text {tapped }}-1.92 \mathrm{Dv} 90_{4 \mathrm{bar}}+2.08 \mathrm{RI}+52.39$ & 0.86 & 0.01 \\
$\mathrm{EF}(\%)_{\mathrm{RS} 01-\mathrm{HR}}=0.39 \mathrm{~T}_{\mathrm{g}}-95.56 \rho_{\mathrm{bulk}}+82.25$ & 0.67 & 0.03 \\
$\mathrm{RF}(\%)_{\mathrm{RS} 01-\mathrm{HR}}=72.56-1.74 \mathrm{Dv} 90_{4 \mathrm{bar}}-3.36 \mathrm{SE}$ & 0.98 & $3.94 \times 10^{-05}$ \\
\hline
\end{tabular}

${ }^{a} \mathrm{RI}=$ rugosity index; $\mathrm{SE}=$ surface protein excess. 